\title{
Hybrid XNBR composites with carbon and aluminosilicate nanofillers
}

\author{
Sylwia Krzemińska, et al. [full author details at the end of the article]
}

Received: 20 November 2018 / Revised: 30 April 2019 / Accepted: 20 May 2019 / Published online: 28 May 2019 (C) The Author(s) 2019

\begin{abstract}
The objective of the work was to investigate the possibility of simultaneous application of different types of nanofillers: graphene oxide with carboxylic groups and modified bentonite nanoparticles to carboxylated acrylonitrile-butadiene rubber (XNBR), and to determine the effect on the structural, mechanical and barrier properties of the composites. The composites were designed for use in protective clothing and gloves. Rubber compounds were crosslinked by a hybrid set with simultaneous use of sulphur (1.5 phr) and magnesium oxide (2.5 phr). Graphene oxide and bentonite particles were characterised by BET test method. The XNBR composites with nanofillers were studied in terms of structure (WAXS) and types of chemical bonds (FTIR), barrier properties against chemical substances (mineral oil) and swelling properties, as well as mechanical properties (puncture resistance, tear resistance, cut resistance, abrasion resistance, tensile strength). Simultaneous incorporation into XNBR of two types of nanofillers, bentonite in the amount of 1.0-4.0 phr and graphene oxide with carboxylic groups in the amount of 1.0-2.0 phr, affected positively the mechanical parameters. The most significant improvement was noted for the parameter specifying the puncture resistance, almost threefold improvement from $34 \pm 2 \mathrm{~N}$ for unfilled XNBR composite to $91 \pm 5 \mathrm{~N}$ for XNBR composite filled with 2 phr of bentonite (XNBR Bent. 2), or one and a half to $56 \pm 5 \mathrm{~N}$ for XNBR composite filled with $2 \mathrm{phr}$ of bentonite and $2 \mathrm{phr}$ of graphene oxide (XNBR Bent 2 GO 2 ). The composites showed equally high resistance to penetration of the selected test chemical-mineral oil. The breakthrough time for XNBR composites without the nanofiller and containing differential amounts of nanofillers was very long and similar to that obtained for the reference sample (480 min).
\end{abstract}

Keywords Carboxylated nitrile-butadiene rubber $\cdot$ Hybrid XNBR composites · Nanofillers $\cdot$ Graphene oxide $\cdot$ Bentonite $\cdot$ BET analyse $\cdot$ Surface area $\cdot$ Resistance to oil $\cdot$ Mechanical properties $\cdot$ Ageing

Electronic supplementary material The online version of this article (https://doi.org/10.1007/s0028 9-019-02825-9) contains supplementary material, which is available to authorized users. 


\section{Introduction}

Polymer composites containing two types of nanofillers are the solution proposed more and more frequently in order to achieve the improvement in their mechanical, thermal, electrical and barrier properties. Hybrid composites containing nanoparticles of carbon nanofillers (graphene, graphene oxide) and aluminosilicates (montmorillonite, bentonite) arouse considerable interest. The use of a different kind of nanoparticles in addition to graphene allows to reduce the production costs of the composites. A synergistic increase in resistance to mechanical factors as well as to permeation by chemicals is also observed. In the case of hybrid composites, a greater improvement in their properties is expected than for the materials with nanoparticles applied separately so far, including the widely used aluminosilicates. A prerequisite for this is the similarity of the layered structure of graphene and aluminosilicates, which can additionally reinforce a polymer composite as a result of better dispersion of the particles in the polymer matrix.

Fillers are typically added to elastomers to improve their properties such as strength, tear, abrasion resistance, but they can also be used to enhance the electrical and thermal conductivity and permeability resistance of a rubber material. Over the past two decades, the nanomaterials with exfoliated layered silicates and carbon nanotubes into elastomers have been explored in detail. The excellent physical properties, high surface area and anisotropy (aspect ratio) of many nanomaterials suggest tremendous promise for their more general use as fillers for elastomers and polymers more generally. Given the recent development of graphene, it is of significant interest to establish effective dispersion techniques for and investigate the use of graphene-based materials for elastomer reinforcement. It is worth undertaking because the content of nanofillers in the rubber compounds is significantly smaller. It amounts to 3-12 phr for layered aluminosilicates and 1-5 phr for graphene and graphene oxide $[1,2]$ which constitutes a significant difference as compared to the conventional fillers, such as carbon black, silica and others, with a content of 20-25 phr. This also represents a major improvement due to the fact that high filler concentrations are technologically unfavourable and increase the product weight.

Bentonite is a layered aluminosilicate area, whose main ingredient is montmorillonite, which is hydrated aluminium hydrosilicate (60-95\%), with the general formula:

$$
\mathrm{M}_{y}^{+}\left(\mathrm{Al}_{2-y} \mathrm{Mg}\right)\left(\mathrm{Si}_{4}\right) \mathrm{O}_{10}(\mathrm{OH})_{2} \times n \mathrm{H}_{2} \mathrm{O}
$$

The other ingredients include mica, pyrites, limestone and quartz. It can absorb water equivalent to 6 times its weight $[3,4]$. It is formed as a result of volcanic glass montmorillisation and occurs in pyroclastic deposits [5].

Montmorillonite (MMT) is made up of three-layer packages, between which there are galleries consisting of free ions. The two outer layers consist of tetrahedral silicon dioxide crystals, between which there is an octahedral layer, consisting of magnesium oxide, iron or aluminium crystals. The layers are connected by common oxygen atoms, which are located at the corners of the tetra- and octahedrons [6]. Negative charges are generated by isomorphic substitutions of cations in the 
tetra- and octahedrons that are balanced by free alkaline cations $\left(\mathrm{Na}^{+}, \mathrm{Ca}^{2+}, \mathrm{H}^{+}\right.$, $\mathrm{Li}^{+}$) in the intercalated area. Inorganic cations in the gallery are exchanged, e.g. to organic cations, so the MMT surface becomes organophilic [7].

The distances between the layers are within the $0.1-2.1 \mathrm{~nm}$ range. The thickness of a single MMT platelet amounts to $9.6 \AA$, and its transverse dimensions range from $300 \mathrm{~nm}$ to several micrometres. The total thickness of a single package along with the space between it and another platelet is called the base distance and amounts to $1.26 \mathrm{~nm}$ (Fig. 1) [8].

The layered structure of MMT results in the ability to absorb water and dissolve in organic solvents, binding surfactants and larger molecules in the intercalated layer, which is used for filling polymer composites. A significant advantage of bentonites is the ability to create gels in water, with thixotropic properties [9, 10]. Natural bentonites are, however, hydrophilic and incompatible with polymers, in particular nonpolar ones, and therefore, they are modified in order to change their nature to organophilic and capable of intercalation, i.e. separation of the layers [9].

Thanks to the specific structure of MMT that contains cations of metals, hydrogen bonds and van der Waals ionic interactions are possible [9, 11].

Graphene in its theoretical form is a two-dimensional carbon monocrystal. With $s p^{2}$ hybridisation of the crystalline lattice, it looks like a honeycomb. There are two principal methods of production, which lead to obtaining different forms of graphene designed for different applications. Top-down methods, like CVD (chemical vapour deposition) [12] or epitaxial methods [13], allow to obtain macroscopic sheets of graphene, with good structure and few defects (mostly related to the growth process). Top-down methods are the second attempt of graphene processing. Flakes are taken from exfoliation of graphite stacks, which contain single-carbon-layer graphene. Thickness of this structure can vary from one atom

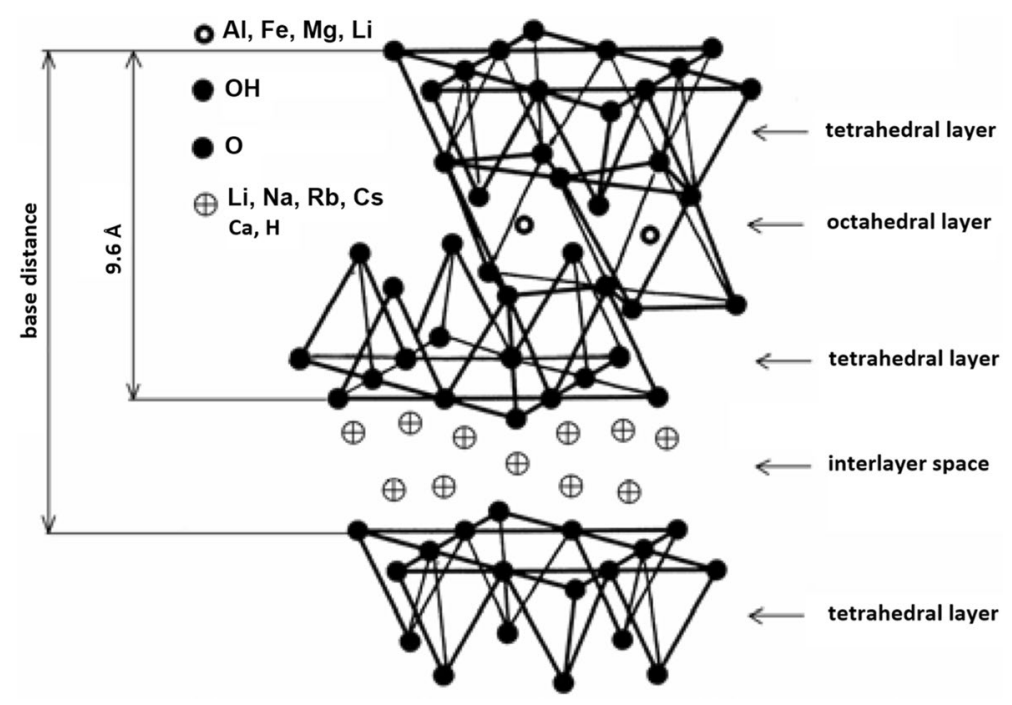

Fig. 1 The structure of montmorillonite [8] 
to a few hundred graphene layers. But only up to 10 layers, the term graphene can be used (there are monolayer, bilayer and few layer types of graphene) [14]. The structure of flake graphene is more defective comparing to epitaxial graphene. Thus, such flake graphene is more reactive and can be chemically modified for best fitting in composites.

Oxidation-reduction is the most common method for obtaining flake graphene. The idea of the process is to use interaction between the polar groups introduced during oxidation to prepare graphite for mechanical separation of graphitic layers. After this process, called exfoliation, the introduced oxygen groups must be removed. This process restores pristine structure of graphene. An intermediate product of the oxidation-reduction method is a graphene oxide (GO) (Fig. 2). The differences between graphene and GO are shown in the structure. The presence of functional groups such as epoxy, hydroxyl, ketone, ester, organosulphate, carboxylic acid groups, sulphate groups changes the hybridisation to $s p^{3}$. Vacancies may also be found in the lattice. The oxygen groups are reactive, and functionalisation with various chemicals is possible. All groups are not removed completely during the reduction process. Therefore, the structure is not the same as in graphene, so to emphasise the differences this kind of material is called reduced graphene oxide (rGO) [15].

The simultaneous use of graphene oxide and modified bentonite nanoparticles as fillers of carboxylated acrylonitrile-butadiene rubber in our work allows to reduce the crosslinking time of this elastomer and increase the degree of crosslinking. XNBR composites with two types of nanofillers are characterised by higher mechanical strength and better tear resistance. The resistance to chemicals is also higher as indicated in the swelling study. Technological difficulties (compression shrinkage) observed during the preparation of such hybrid XNBR compositions are the main disadvantages of the presented method. In addition, used hybrid crosslinked set to XNBR is characterised by a lower cost of production and much better application properties.

The aim of the work was to determine the effect of graphene oxide and modified bentonite nanoparticles application to carboxylated acrylonitrile-butadiene rubber (XNBR) on the structure, mechanical and barrier properties of the

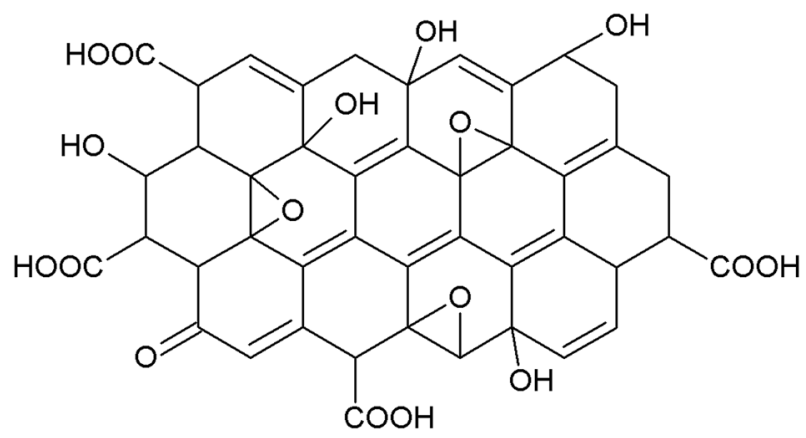

Fig. 2 Exemplary structure of graphene oxide (fragment of the structure) 
composites, intended for protective clothing, gloves and shoes. Characterisation of nanocomposites was carried out by WAXS, FTIR, analysis and testing of mechanical and barrier properties. Graphene oxide and bentonite particles before the application to XNBR were characterised by BET test method.

\section{Experimental part}

\section{Materials}

The object of the study was carboxylated acrylonitrile-butadiene rubber (XNBR) (Lanxess $\mathrm{GmbH}$, Germany) with $27 \%$ bound acrylonitrile content, $7 \%$ content of bound carboxylic acid, $0.99 \mathrm{~g} / \mathrm{cm}^{3}$ density, Mooney viscosity [ML $(1+4) 100{ }^{\circ} \mathrm{C}$ ] $47 \pm 5$. XNBR was crosslinked by a hybrid set with simultaneous use of sulphur (article number 527795704, content: $99.85 \%$, bulk density $400-500 \mathrm{~kg} / \mathrm{m}^{3}$ ) from Chempur (Poland) and magnesium oxide (trade name Active Mag 140, density $300 \mathrm{~g} / \mathrm{L}$, content $98.5 \%$ ) from Van Mannekus \& Co. B.V. (The Netherlands).

XNBR was crosslinked in the presence of zinc diethyldithiocarbamate as an accelerator (trade name LUVOMAXX ZDEC, density: $1.480 \mathrm{~g} / \mathrm{cm}^{3}$ at $20{ }^{\circ} \mathrm{C}$, bulk density: $330-370 \mathrm{~kg} / \mathrm{m}^{3}$, practically insoluble in water) manufactured by Lehmann \& Voss \& Co.KG (Germany), stearic acid as a dispergator (trade name Tefacid RG, acid value 194-210, iodine value $\leq 8$, carbon chain $\mathrm{C}_{18}: 50-70 \%$ ) manufactured by AarhusKarlshamn (Sweden) and 2,2'-methylene-bis[(6-(1-methylcyclohexyl)]$p$-cresol as an antioxidant (trade name LOWINOX WSP, water solubility: $<0.01 \mathrm{~g}$ / $\mathrm{dm}^{3}$ ) purchased from Enkev Polska Sp. z o.o (produced by BASF, Germany).

\section{Aluminosilicate nanofiller (bentonite)}

A small amount of aluminosilicate nanofiller in the form of a modified bentonite (trade name Bentonite Special BS, manufactured by ZGM Zębiec, Poland, Table 1 in Supporting Information)-1.0, 2.0, 3.0 or $4.0 \mathrm{phr}$, was introduced into rubber, marking the composites with appropriate symbols: XNBR Bent. 1, XNBR Bent. 2, XNBR Bent. 3, XNBR Bent. 4, respectively, or the aluminosilicate nanofiller in a fixed quantity of $2 \mathrm{phr}$ and a carbon nanofiller in the form of graphene oxide in the amount of 1.0 or $2.0 \mathrm{phr}$ were introduced at the same time, marking the composites with appropriate symbols: XNBR Bent. 2 1, XNBR Bent. 2 GO 2, respectively, obtaining in this way hybrid XNBR composites containing two different types of nanoparticles.

Bentonite was modified with the use of QAS modifier (BASF) quaternary ammonium salts $\left(\mathrm{R}_{1} \mathrm{R}_{2} \mathrm{R}_{3} \mathrm{R}_{4} \mathrm{~N}^{(+)} \mathrm{Cl}^{(-)}\right)$, where $\mathrm{R}_{1}=3$-chloro-2-hydroxypropyl substituent, $\mathrm{R}_{2}, \mathrm{R}_{3}$ and $\mathrm{R}_{4}=$ methyl substituents.

The modification process is carried out in accordance with the developed and patented procedure $[16,17]$ in $10 \%$ aqueous suspension of enriched Bentonite Special (BS). In the suspension, heated to the temperature of $70^{\circ} \mathrm{C}, 3$-chloro-2-hydroxypropyl tetramethylammonium chloride (QAS) was introduced dropwise in the form of $50 \%$ solution in ethanol. The used amount of QAS was $35 \mathrm{~g} / 100 \mathrm{~g}$ raw bentonite. 
After instillation of the entire portion of the QAS solution, the reaction mixture was heated gradually to $80{ }^{\circ} \mathrm{C}$ with vigorous stirring and maintained in such condition for $3 \mathrm{~h}$. After that time, the mixture was cooled gradually to room temperature with vigorous stirring during $1 \mathrm{~h}$. The modified bentonite sediment was separated from the reaction mixture by filtering it under vacuum on a Büchner funnel, washing repeatedly with distilled water. The resulting sludge was dried in a forced air chamber at the temperature of $100-120{ }^{\circ} \mathrm{C}$ to achieve the humidity $\leq 0.5 \%$ of the mass. The dried sludge of modified bentonite was milled in a shock and ball mill and then sieved through the screens with the mesh diameter of $0.06 \mathrm{~mm}$.

To obtain information about the efficiency of the modifications process, a DSC analysis of unmodified bentonite (BS) and modified QAS bentonite (BSQAS) was performed. The measurement was performed using a Mettler Toledo DSC $822^{\mathrm{e}}$ type camera with the following parameters: measurement time, $45 \mathrm{~min}$; temperature range, $0.0-450{ }^{\circ} \mathrm{C}$; heating rate, $10{ }^{\circ} \mathrm{C}$. Specific surface area measurements, basing on the BET isotherm of adsorption, were taken using a Quadrasorb Evo analyser (Quantachrome Instruments). This apparatus consists of a FLOVAC Degasser degassing station and an analytic station. This fully automatic system allows to measure specific surface area in the range from 0.01 to $6000 \mathrm{~m}^{2} \mathrm{~g}^{-1}$. Before the measurements, the samples of bentonite were dried for $24 \mathrm{~h}$ at $423 \mathrm{~K}$ and degassed in vacuum $(0.6 \mathrm{~Pa})$ for $5 \mathrm{~h}$ at the same temperature. Adsorption measurements were carried out using nitrogen at temperature $77 \mathrm{~K}$. Žunić et al. [18] for analysis of textural properties (surface area) of bentonite used mercury intrusion porosimetry. For each of the three analysed samples were collected 13 measuring points in the relative pressure range $0.05-0.19 \mathrm{p} / \mathrm{p} 0$. The average of three measurements for bentonite before the modification is $15.358 \mathrm{~m}^{2} \mathrm{~g}^{-1}$ and after modification process is slightly larger $15.763 \mathrm{~m}^{2} \mathrm{~g}^{-1}$. As Ghorbanpour indicated, the reason for the surface increase can be diffusion of iron ions to the bentonite [19].

On DSC studies of unmodified BS within the $50-100{ }^{\circ} \mathrm{C}$ temperature range, the release of moisture absorbed by the sample and water from the crystal lattice is observed. Similar effects of slightly lower intensity are observed to occur within the $40-100{ }^{\circ} \mathrm{C}$ temperature range for modified QAS bentonite (BSQAS). In addition, the effect associated with the distribution of the modifier-QAS, within the 220-290 ${ }^{\circ} \mathrm{C}$ temperature range and associated with the distribution of the tertiary amine within the $370-440{ }^{\circ} \mathrm{C}$ temperature range was observed for BSQAS (Table 2 in Supporting Information).

To obtain information about the efficiency of bentonite modifications process (separation of aluminosilicate platelets), X-ray examinations of unmodified bentonite (BS) and modified QAS bentonite (BSQAS) in powder form were performed. The determinations were performed for the powdered filler using the wide-angle X-ray scattering technique (WAXS) using a Drone 234 type X-ray diffractometer equipped with $\mathrm{CuK}_{\alpha}$ lamp. For the calculation of the interplatelet distances, signals for the 001 lattice plane were selected [20]. The distance between the bentonite platelets was calculated according to the Bragg formula.

On the basis of the obtained research results (Table 3 in Supporting Information), it was found that the distance between the platelets $\left(\mathrm{d}_{001}\right)$ of unmodified BS and modified BSQAS had significantly increased from 12.6 A for BS to approx. 22.2 
that for BSQAS. A larger $\mathrm{d}_{001}$ value means facilitated migration of the polymer chains between the filler layers, which promotes comminution of the aluminosilicate platelets to the size of nanoparticles. The platelet separation value of the tested modified bentonites, as well as the platelet sizes calculated according to the Scherrer formula [21], is summarised in Table 3 in Supporting Information.

\section{Carbon nanofiller: graphene oxide with introduced carboxylic groups}

Nanofiller: graphene oxide with introduced carboxylic groups $\left(\mathrm{GO}_{\mathrm{COOH}}\right)$ prepared from natural graphite (Asbury \#1 Large flakes), was obtained from the Institute of Electronic Materials Technology, Poland. Graphene oxide was prepared using the modified Hummer method. The used reagents included sulphuric acid 96\% (Chempur) $750 \mathrm{~mL}$, sodium nitrate (Chempur) $16.5 \mathrm{~g}$, potassium permanganate (Chempur) $90 \mathrm{~g}$, hydrogen peroxide $30 \%$ (Chempur) $30 \mathrm{~mL}$, hydrochloric acid 3\%. Sodium nitrate was added to sulphuric acid and mixed until dissolved completely, then graphite was added, and stirring was continued. The temperature was lowered to $5{ }^{\circ} \mathrm{C}$, and potassium permanganate was added in a few portions. After that, the reaction mixture reaction was heated to $35{ }^{\circ} \mathrm{C}$ and mixed for several hours. Finally, the temperature was raised to $95{ }^{\circ} \mathrm{C}$ and maintained for $15 \mathrm{~min}$. The postreaction slurry was diluted in water, and after that hydrogen peroxide was added. The purification commenced with washing three times in hydrochloric acid and then several washing cycles in deionised water. Purified graphene oxide was exfoliated by the ultrasound probe $(500 \mathrm{~W}, 30 \mathrm{~min}$, ampl. $75 \%$ ). Then, the reduction process was conducted. Citric acid monohydrate (Chempur) in the ratio of $1 \mathrm{~g}$ of acid per each $0.08 \mathrm{~g}$ of dry $\mathrm{GO}$ and GO suspension was used for the reaction. The reduction conditions were set on $180{ }^{\circ} \mathrm{C}$ and $12 \mathrm{~h}$ in volume of $300 \mathrm{~mL}$. After the reaction, the sediment was purified and dried.

Basic information about the process of reduction comes from elemental analysis (Model: Vario Micro, Producer: Elementar Analysensysteme $\mathrm{GmbH}$ and for oxygen Model: EA 1108 Producer: Carlo Erba). Two samples, 1 g each, were taken for the analysis. A difference between the results is at the level of 0.2 per cent points was obtained. Elemental composition of $\mathrm{GO}_{\mathrm{COOH}}$ indicated that the mass percentage of individual elements is as follows: $\mathrm{C} 79.5 \%, \mathrm{H} 2.9 \%, \mathrm{~N}<0.3 \%, \mathrm{~S}<0.3 \%$ and $\mathrm{O}$ $16.5 \%$.

The sample contains $16.5 \%$ of oxygen, which means the reduction is not complete, and some of the functional groups are still present. Low content of sulphur can exclude the presence of amine and thiol groups.

Infrared spectra were collected by using a Bruker vacuum FTIR spectrometer Vertex $80 \mathrm{v}$. A total of $1.0 \pm 0.1 \mathrm{mg}$ of $\mathrm{GO}_{\mathrm{COOH}}$ was mixed with $320 \pm 0.1 \mathrm{mg}$ of finely ground $\mathrm{KBr}$ and put into a pellet-forming die. The 13-mm-diameter pellets were formed under a vacuum to eliminate air moisture from the $\mathrm{KBr}$ powder. The IR absorbance spectra were recorded in the range $400-4000 \mathrm{~cm}^{-1}$ with a spectral resolution of $2 \mathrm{~cm}^{-1}$. The obtained spectra were corrected for the absorption of $\mathrm{KBr}$ pellet by subtracting the absorption spectrum of pure $\mathrm{KBr}$ pellet from the spectra of the samples. The transition method was used. 


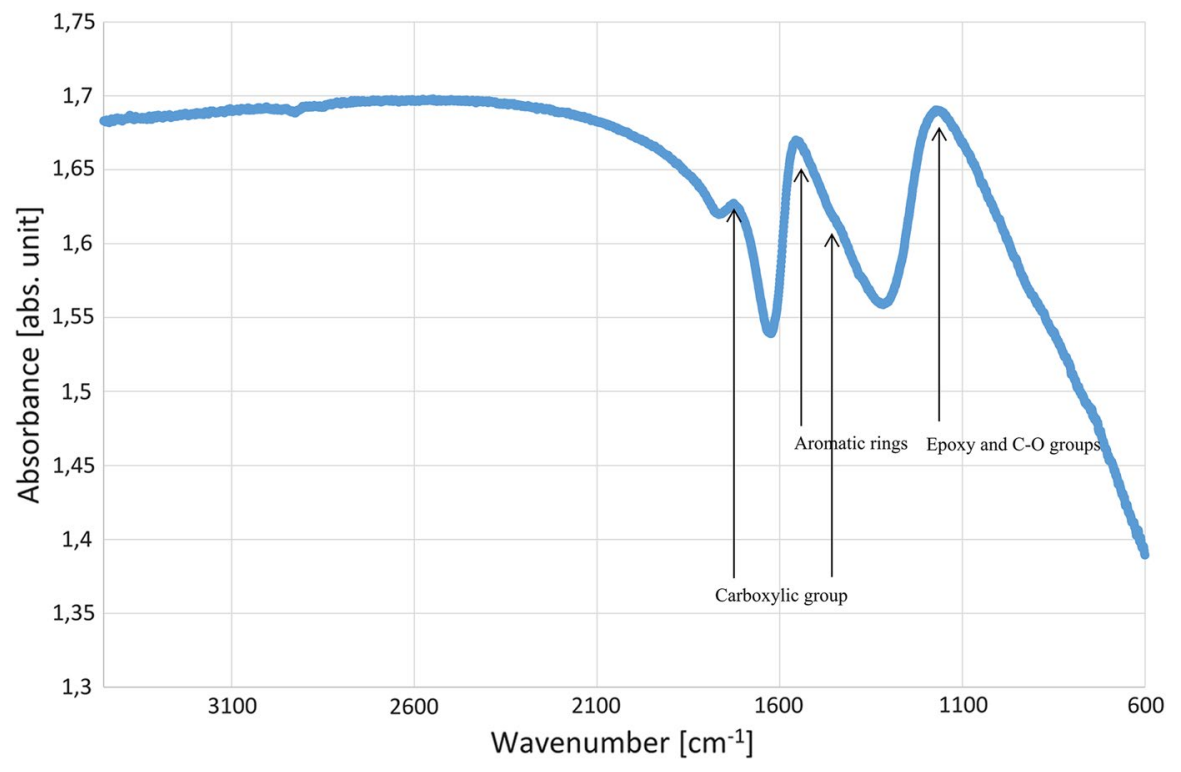

Fig. 3 Infrared absorption of $\mathrm{GO}_{\mathrm{COOH}}$

The infrared spectra indicate that obtained material is partially reduced. A peak at $1726 \mathrm{~cm}^{-1}$ can be interpreted as stretching vibrations from $\mathrm{C}=\mathrm{O}$ bonds from carboxylic groups. A band at $1627 \mathrm{~cm}^{-1}$ corresponds to the COO-symmetric vibrations, and the $1580 \mathrm{~cm}^{-1}$ peak from $\mathrm{C}=\mathrm{C}$ (and $\mathrm{C}-\mathrm{C}$ ) bond from aromatic rings (Fig. 3). The band at $1170 \mathrm{~cm}^{-1}$ is from $\mathrm{C}-\mathrm{O}-\mathrm{C}$ i C-O bonds. In the spectra, signal from hydroxyl group is not observed. (The signal should be observed at $3400 \mathrm{~cm}^{-1}$.) The hydroxyl group is removed during selected reduction, and similar effect can be obtained by flash irradiation [22].

The infrared spectra indicate that obtained material is partially reduced. A peak at $1726 \mathrm{~cm}^{-1}$ and weak peak in $1430 \mathrm{~cm}^{-1}$ can be interpreted, respectively, as stretching vibrations from $\mathrm{C}=\mathrm{O}$ and $\mathrm{H}-\mathrm{O}$ bonds from carboxylic groups. The $1560 \mathrm{~cm}^{-1}$ peak corresponds to $\mathrm{C}=\mathrm{C}$ (and $\mathrm{C}-\mathrm{C}$ ) bond from aromatic rings. The band at $1170 \mathrm{~cm}^{-1}$ is from $\mathrm{C}-\mathrm{O}-\mathrm{C}$ and $\mathrm{C}-\mathrm{O}$ bonds. In the spectra, signal from hydroxyl group is not observed. (The signal should be observed at $3400 \mathrm{~cm}^{-1}$.) The hydroxyl group is removed during selected reduction, and similar effect can be obtained by flash irradiation [22].

For identification of the material, Raman spectroscopy was conducted (via confocal Raman microscope, Reinshaw). In observed spectra, one can see two peaks, D and G, giving an information about carbon species: breathing modes of carbon sixfold rings or defects and vibrations of carbon chains, respectively. D-band is higher than G-band which indicates that flakes were not fully reduced. Intensity ratio between $\mathrm{D}$ and $\mathrm{G}$ peaks is 0.95 (Fig. 4). For chemical reduced GO, this ratio is on the level of 0.93 or lower, when GO peaks ratio is on the level of 1 or more [23]. What's more, both bands should be well separated, while in our case there is a saddle between D and G bands. This may be due to some oxygen 
Fig. 4 Raman spectra of $\mathrm{GO}_{\mathrm{COOH}}$

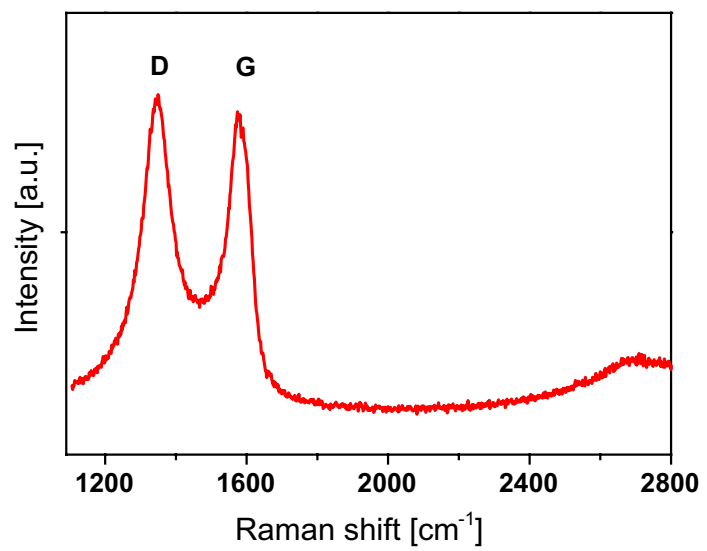

groups still present on rGO flakes, like epoxy, hydroxyl or carboxy ones, or even $\mathrm{C}-\mathrm{H}$ groups [24]. Broadening of D peak gives information about defects of graphene, like carbon vacancies, fivefold, sevenfold or eightfold carbon rings or still attached oxygen groups, when $\mathrm{G}$ is a graphitic signature of material [25]. Lower ratio between $\mathrm{D}$ and $\mathrm{G}$ peaks indicates more of $s p^{2}$ carbon atoms, which is caused by the reduction in graphene oxide.

The obtained SEM images are typical of rGO. The surface is well developed. Impurities are not observed (Fig. 5). The confirmation of surface properties is based on the BET isotherm of adsorption analysis, performed on Quadrasorb Evo analyser. The same procedure as in the case of bentonite was used. The only difference was reduction in temperature for drying and degassing of material $315 \mathrm{~K}$. The specific surface of sample was within the $248-315 \mathrm{~m}^{2} / \mathrm{g}$ range (based on five samples) [26, 27].

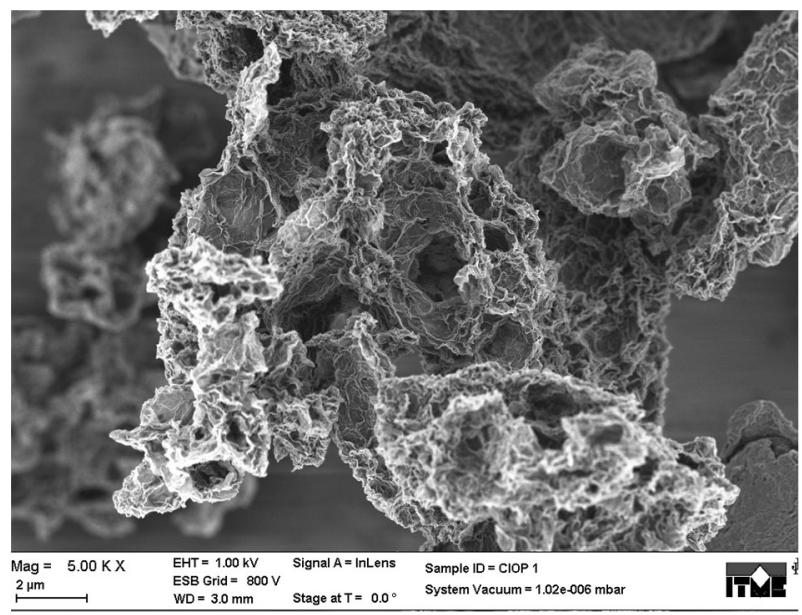

Fig. 5 A SEM image of $\mathrm{GO}_{\mathrm{COOH}}$ surface (magnitude: $2000 \mathrm{~K}$, energy of electron beam: $1 \mathrm{kV}$, sensor: in-lens) 


\section{Formulation of composites}

The formulations of rubber composites are presented in Table 1. The composition of the mixture and the hybrid crosslinking method with simultaneous use of sulphur and a metal oxide in the presence of the ultraaccelerator are the subject of a patent application [28].

\section{Preparation of samples}

Rubber compounds were prepared by the conventional method using a laboratory two-roll mill with $100 * 200 \mathrm{~mm}$ rolls, at a roll temperature of $20-25{ }^{\circ} \mathrm{C}$ and friction of $1: 1.1$. Mixing was conducted for up to $11 \mathrm{~min}$, until all the components were blended and thoroughly mixed. The compounds were stored at ambient temperature. The mixing procedure was as follows: step 1-preparation of the premix mixture (XNBR + dispersant + accelerator + antioxidant + magnesium oxide), $6 \mathrm{~min}$ and division of the premix mixture into parts (sulphur was added to one part immediately_reference composite); step 2-introduction of fillers, 3 min; step 3-introduction of sulphur, $1 \mathrm{~min}$; step 4-homogenisation of the mixture, $1 \mathrm{~min}$.

In order to ensure optimum crosslinking conditions (time and temperature), vulcametric measurements were conducted according to the standard PN-ISO 3417:1994 [29], using a WG-02 oscillating disc vulcameter with a disc amplitude of $\pm 3^{\circ}$ and oscillation frequency of $1.7 \pm 0.1 \mathrm{~Hz}$. Rheometric properties of XNBR composites are given in Table 2.

Composite samples were produced in steel moulds with a diameter of 80 or $150 \mathrm{~mm}$. The moulds containing crude XNBR compounds were placed between electrically heated $\left(140^{\circ} \mathrm{C}\right)$ plates of a hydraulic press, between two Teflon sheets; the heating time was $30 \mathrm{~min}$. Subsequently, the samples were allowed to stand for $24 \mathrm{~h}$ and then removed from the dies. The width variation of the samples was $0.43-0.60 \mathrm{~mm}$.

\section{Test method}

\section{Wide-angle X-ray scattering (WAXS)}

WAXS was used to study the nature of nanofillers dispersion in the composites. WAXS was performed with an URD 63 (Seifert, Germany) diffractometer using $\mathrm{CuK}_{\alpha}$ radiation and the following settings: accelerating voltage $-40 \mathrm{kV}$, anodic current $-30 \mathrm{~mA}$. Radiation was monochromatised with a nickel filter and impulse height discriminator. A scintillation counter was used as a detector. X-ray diffractograms of the composite materials were obtained by the stepwise method within a diffraction angle range of $3^{\circ}-60^{\circ}$, with a step of $0.1^{\circ}$. The impulse counting time was $15 \mathrm{~s}$ in all cases. 


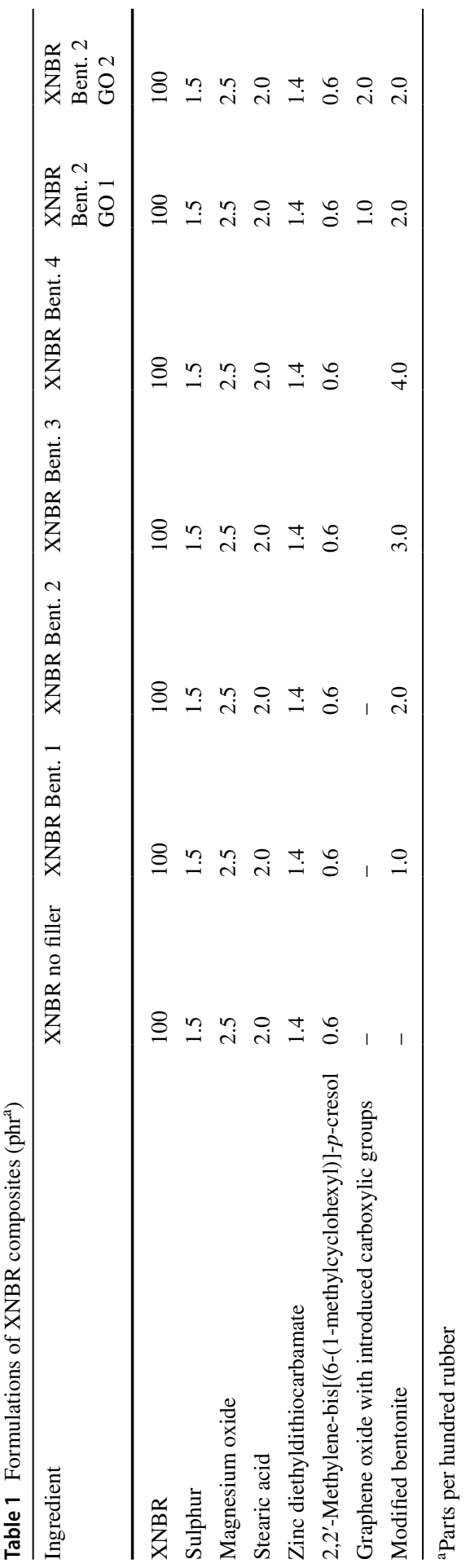


Table 2 Rheometric properties of XNBR composites crosslinked at $140{ }^{\circ} \mathrm{C}$

\begin{tabular}{lllll}
\hline Composite & $L_{\min }(\mathrm{dNm})$ & $\Delta L_{30}(\mathrm{dNm})$ & $\tau_{02}(\mathrm{~min})$ & $\tau_{90}(\mathrm{~min})$ \\
\hline XNBR no filler & 18.3 & 46.7 & 2.3 & 26.6 \\
XNBR Bent. 1 & 17.6 & 47.4 & 1.7 & 39.9 \\
XNBR Bent. 2 & 19.0 & 51.0 & 1.5 & 32.3 \\
XNBR Bent. 3 & 19.3 & 53.7 & 1.5 & 31.0 \\
XNBR Bent. 4 & 22.5 & 51.3 & 1.6 & 32.4 \\
XNBR Bent. 2 GO 1 & 24.7 & 63.5 & 1.8 & 26.9 \\
XNBR Bent. 2 GO 2 & 23.5 & 61.0 & 1.9 & 26.6
\end{tabular}

$L_{\text {min }}$, minimal torque; $\Delta L_{30}$, torque increment after 30 min of heating; $\tau_{02}$, scorch time; $\tau_{90}$, cure time

\section{Fourier transform infrared spectroscopy (FTIR) studies}

The infrared spectroscopy (FTIR) studies were carried out with the use of a spectrophotometer (Nicolet 6700, Thermo Scientific, USA), equipped with a "MTEC 300" photoacoustic attachment. The resolution of $4 \mathrm{~cm}^{-1}$ and the measuring field purge with helium 5.0 were applied. The spectra, after correction of the distortions associated with the presence of water vapour, were averaged from three measurements after 128 scans in each measurement. The test samples took the form of fragments of membrane materials of approx. $5 \times 5 \mathrm{~mm}$ size. The measured surface of the sample was not subjected to any mechanical influences.

\section{Testing of mechanical properties}

The mechanical properties of XNBR composites were characterised by the determination of their resistance to:

- tearing,

- puncture,

- disruption,

- cutting,

- abrasion.

The tear resistance test was performed with the use of a universal testing machine (type 4880, Instron, USA). The samples of $50 \times 100 \mathrm{~mm}$ dimensions were mounted in jaws situated at a distance of $40 \mathrm{~mm}$ from each other. The beam speed was $100 \mathrm{~mm} / \mathrm{min}$. The results are expressed as means for four samples.

Resistance to puncture was determined with the use of a universal testing machine (type 4880, Instron, USA). During the puncture resistance test, the specimens with a diameter of not less than $40 \mathrm{~mm}$ were exposed to a pin puncturing the sample at a $100 \mathrm{~mm} / \mathrm{min}$ speed. The results are expressed as means for three samples.

Tensile elongation at break was determined in accordance with PN-ISO 37:1998 [30] using a testing machine (type 1435, Zwick GmbH \& Co. KG, Germany) 
coupled with a computer with appropriate software. The test samples used were oar-shaped with $4 \mathrm{~mm}$ width of the measuring section and $2 \mathrm{~mm}$ thick, which were stretched with a constant speed of $500 \mathrm{~mm} / \mathrm{min}$ using the testing machine until the sample was disrupted. The results are expressed as means for five samples.

Resistance to cutting was determined using the cut resistance testing apparatus (CoupTest type, Artec Testnology, Netherlands). Samples of $100 \times 60 \mathrm{~mm}$ size, subjected to the operation of a wheel-shaped blade, were analysed. Owing to special software, the testing equipment counted the number of cycles at which the intersection of the sample occurred. The results are expressed as means for two samples.

Abrasion resistance was determined using a standard tester (Nu-Martindale, James H. Heal Ltd., Great Britain). Sandpaper with a minimum surface weight of $125 \mathrm{~g} / \mathrm{m}^{2} \pm 5 \%$ was used as the abrasive material. The pressure exerted on the samples during abrasion was $9(0.2 \mathrm{kPa})$. The condition of the samples surface was evaluated organoleptically after a specified number of cycles: 100, 500, 2000 and 8000 cycles. The results are expressed as means for four samples.

The tests for resistance to puncture, tear, cut and abrasion were performed according to the PN-EN 388:2006 standard [31], specifying the mode of testing the mechanical strength properties of all-rubber products designed to protect against mechanical hazards.

Prior to the tests, the samples were conditioned in air at $21 \pm 3{ }^{\circ} \mathrm{C}$ and a relative humidity of $50 \pm 5 \%$.

\section{Testing of barrier properties}

Resistance to permeation by oils Resistance of composites to permeation by mineral oils was determined in accordance with PN-EN 374-3:2005 and EN 6529:2005 [32, 33], which describe and specify the tests of glove and clothing materials designed to protect against chemicals. The designated protection parameter is standardised penetration detection time assumed as "the period of time from the moment of contact of the material with the chemical until the moment when the velocity of the liquid permeating through the tested material reaches a value equal to $1 \mu \mathrm{g} / \mathrm{cm}^{2} \mathrm{~min}$ ".

During the test, the sample of the test material coffin there was placed between two chambers of the permeation cell in such a way that its external surface (right side) was in direct contact with mineral oil, and the inner surface (wrong) was in direct contact with a solid collector medium (filter). A glass fibre filter (GF and GF/C-type manufactured by Whatman, Great Britain) was used as the solid collector medium in the lower compartment of the cell. Then, a portion of mineral oil $(10 \mathrm{~mL})$ was poured into the inlet of the upper chamber of the cell. From that point on, recording of the test duration was commenced.

The test was carried out in the so-called interval system. At certain time intervals $(10,30,60,120,240$ and 480 min since the start of the study), consistent with the boundaries of the protection classes specified in the PN-EN 14605 and PN-EN 374-1 standards [34, 35], presenting the requirements for materials, the filter was collected for analysis. The collected filter was replaced with a new one. Although this method did not allow continuous monitoring of the permeation process, it was necessary due to the type of the collector medium (solid medium) used. To carry 
out quantitative determination of the components of penetrating oily substances, absorbed by solid collector medium, the filters were subjected to extraction using an organic solvent (cyclohexane), assisted ultrasonically (sonication).

Quantitative determination of mineral oil collected in the medium was conducted in accordance with PN-EN ISO 9377-2:2003 [36], using the technique of gas chromatography with flame ionisation detection. A trace GC gas chromatograph (Thermo Fisher Scientific, USA) equipped with a flame ionisation detector (FID) and a capillary chromatographic column (Rtx-5, length $30 \mathrm{~m}$, internal diameter $0.25 \mathrm{~mm}$ ) was used. This testing method was presented by the authors in a prior publication [37].

One type of mineral oil, i.e. the reference oil, representative for mineral oils with a low content of additives, was selected for the tests. Due to the fact that commercially available oils, even of the same variety and derived from the same source, can vary considerably in their composition, the reference oil described in PN-ISO 1817:2001 as Oil no 3 [38] was used. This oil is a mixture of fractions of specially treated oils from naphthenic petroleum (oil IRM 903 according to ASTM D 471; product of Calumet Specialty Products Partners, L.P., USA).

The results are expressed as means for three samples.

Resistance to swelling The swelling test was conducted by immersing for $72 \mathrm{~h}$ the material samples into a solvent: toluene and 2-butanone for $72 \mathrm{~h}$. The samples were weighed before immersion and after immersion. Next, the samples were dried at $40{ }^{\circ} \mathrm{C}$ for $24 \mathrm{~h}$ and then weighed. The procedure was analogous to that used in our previous work [39].

Resistance to exposure to seawater To test the resistance of XNBR composites to seawater, the organoleptic method was applied to evaluate the condition of the sample surface. The tests were carried out using the seawater substitute solution prepared according to the PN-C-06502:1966 standard [40] for research under laboratory conditions. The purpose of the research was to determine whether the sample surface is affected by contact with the medium such as the seawater substitute.

The laboratory tests involve bringing the samples of selected composite variants into contact with seawater substitute solution in lidded beakers. The duration of the material exposure to seawater substitute solution amounted to $0,2,4,6,8,12$ weeks. The sample was exposed to a water column of $10 \mathrm{~cm}$ height. Before and after each period of exposure, a visual inspection of the sample surface was carried out and photographs were taken.

\section{Methodology of statistical analyses of results}

The results of tests of mechanical parameters (resistance to tearing, abrasion, puncture, cutting, tensile strength) were not characterised by normal distribution, and therefore, the analysis of significance was carried out using nonparametric tests. The differences between composite for each parameter were analysed separately using the nonparametric Mann-Whitney $U$ test (when 2 composites were compared) or 
Kruskal-Wallis test and post hoc Dunn tests (when 3 or more composites were compared). The test probability at the level of $p<0.05$ was adopted as a significance level, whereas the level of $p<0.01$ probability was adopted as a high significance level. The analyses of the results were conducted using the PQStat ver. 1.6 statistical package.

Due to the lack of differences between the results of the tests of mineral oil penetration resistance between the composite variants, the statistical analysis of the significance of differences was not conducted.

\section{Results and discussion}

\section{Rheometric studies}

The torque increment $\Delta L$ after $30 \mathrm{~min}$ of heating (Table 5) increased for XNBR composites with nanofillers. The increase was slightly approx. 1.5-10\% for XNBR composites with modified bentonite only, and the most significant increase was observed for XNBR with $3 \mathrm{phr}$ of bentonite-from $46.7 \mathrm{dNm}$ (no filler) to 53.7 $\mathrm{dNm}$ ( $3 \mathrm{phr}$ of bentonite). It can be clearly deduced that an increase in the amount of bentonite leads to a higher values of the torque increment $\Delta L$. A much larger increase was recorded for hybrid XNBR composites with two types of different nanofillers: bentonite and graphene oxide after special preparation to obtain a carboxylic group on the surface. In that case, the torque increment $\Delta \mathrm{L}$ increased by approx. $35 \%$, reaching the value of $63.5 \mathrm{dNm}$ for XNBR composite with $2 \mathrm{phr}$ of bentonite and $1 \mathrm{phr}$ of graphene oxide. It was a good effect of nanofillers application because, as known from the literature, the increase in torque increment is reflected in the crosslink density and afterwards influences on the mechanical properties of the composites [41]. The increase in the torque increment is necessary to improve the tensile strength at break and stress at elongation. The enhancement of torque increment for XNBR composites with graphene oxide and bentonite could probably have an effect on the improvement of mechanical properties.

The obtained cure time $\tau_{90}$ for XNBR composites varied depending on the type of the introduced nanofiller. The cure time increased sharply by $50 \%$ from 26.6 to $39.9 \mathrm{~min}$ for the XNBR composite with $1 \mathrm{phr}$ of bentonite (Table 5). A further increase in the quantity of bentonite to $4 \mathrm{phr}$ resulted in shortening of the cure time. Simultaneous application of two types of fillers: bentonite and graphene oxide, did not affect the cure time compared to neat XNBR.

Different observations were made by Smaoui in the course of studies on the highperformance nanocomposite materials based on carboxylated acrylonitrile-butadiene rubber (XNBR) latex with graphene oxide $(\mathrm{GO})$, or reduced graphene oxide (rGO). He stated that in both XNBR/GO and XNBR/rGO compounds, the cure time increased continuously with the increasing load of the fillers loading. The cure time increased from 13.85 min for neat XNBR to maximally $23.91 \mathrm{~min}$ for XNBR composite with 1 phr of reduced GO [42]. He deduced that the presence of carbon-based fillers can extend the induction period and delay the curing time of vulcanisation. Indeed, free radicals are generated from sulphur, during the vulcanisation process, 
and reacted with the matrix forming crossed linking points. On adding GO sheets, the functional oxygenic groups presented on their surface will absorb the free radicals. Hence, the reactivity of free radicals was reduced and the vulcanisation process was delayed.

\section{Examination of nanomaterial structure using WAXS}

The purpose of the research was to determine the influence of the type and content of the nanofiller introduced to XNBR crosslinked with sulphur and magnesium oxide on the degree of separation of aluminosilicate platelets or graphene layers.

The results of WAXS studies of XNBR composite are presented in Fig. 6 and Table 3.

The results of the tests carried out by wide-angle X-ray scattering (WAXS) on XNBR composites with hybrid crosslinking using two crosslinking agents of different compositions and containing two types of selected fillers demonstrated that the use of aluminosilicate filler in the form of modified bentonite, both as a single filler and optionally as the second nanofiller (together with graphene oxide functionalised

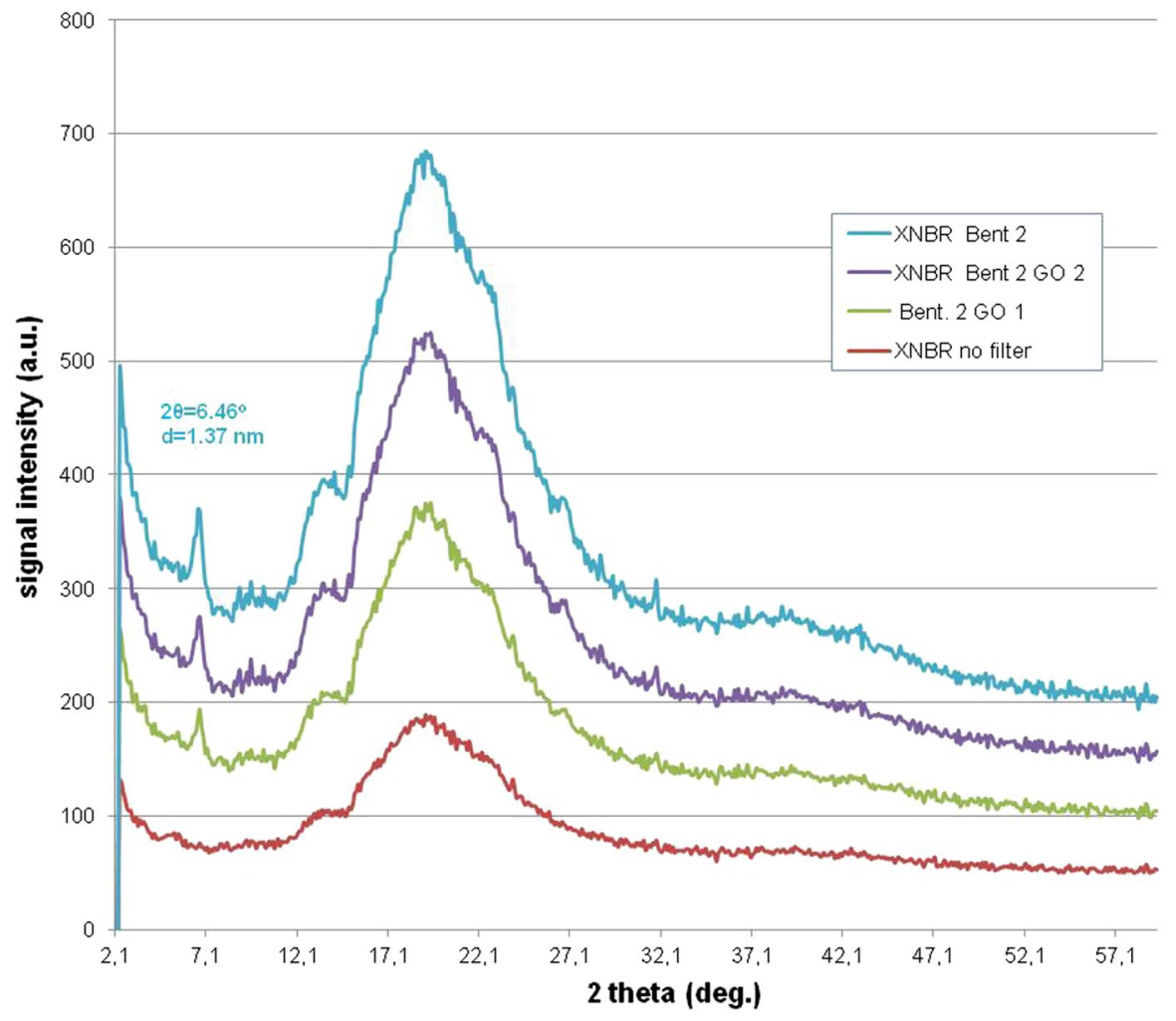

Fig. 6 WAXS curves for XNBR composites: without nanofillers, with bentonite only and hybrid composites with two types of nanofillers (bentonite and graphene oxide) 


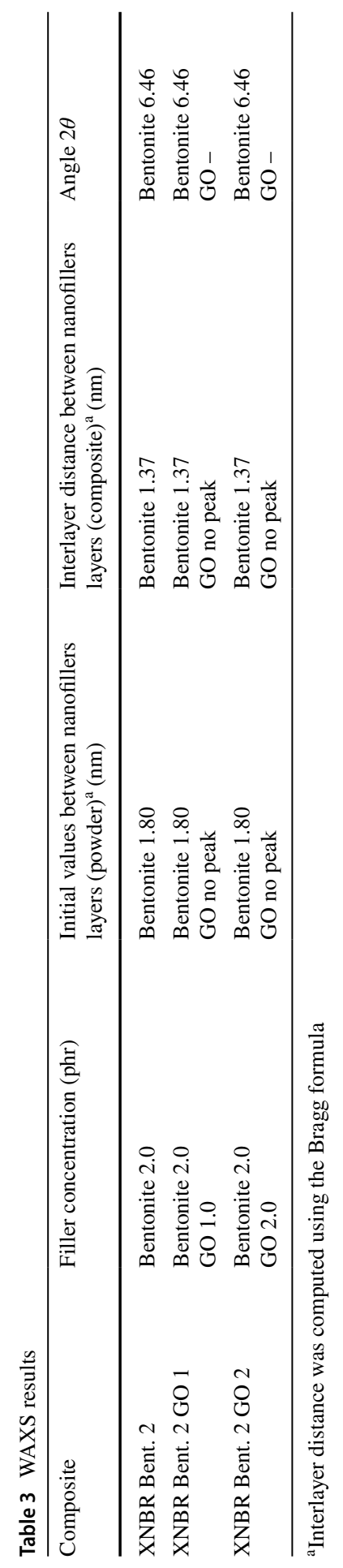


with carboxylic groups), caused a reduction in the distance between the layers of the nanofiller occurring by itself in the form of powder and in the produced composites (Table 3). Reduction in the interlayer distance was identical for XNBR composites and amounted to $4.3 \AA$ (from 1.8 to $1.37 \mathrm{~nm}$ ) (Fig. 6), regardless of the variant of the crosslinking and filling composites. Reducing the distance between the bentonite layers in the produced XNBR composites may promote formation of agglomerates, which is an unfavourable phenomenon, as it is not conducive to good dispersion of the nanofiller in the rubber matrix and results in worse mechanical strength properties.

In turn, in the case of the introduction of the graphene oxide with carboxylic groups to XNBR as one of the two fillers in the absence of the characteristic peak on the WAXS curve, it was concluded that exfoliation between the graphene layers had occurred and the GO structure had not been destroyed in the process of introducing it to the XNBR mix, which is a very positive result. According to the literature data, the WAXS graphite (graphene) curves are characterised by a strong single maximum, whose angular position is $2 \Theta \approx 26^{\circ}$. For graphene oxide $(\mathrm{GO})$, the peak is shifted to the $2 \Theta \approx 10.6^{\circ}$ location $[43,44]$. The lack of the peak characteristic of graphene oxide evidences that exfoliation took place between the graphene layers we are dealing with single graphene layers. The introduction of that nanofiller in the powder form to the rubber did not result in the destruction of its structure, which is a very positive result. It can be assumed that graphene oxide with carboxylic groups, due to the content of these carboxylic groups on the surface of the particles, giving it a more polar structure than bentonite, dispersed much easier polar, carboxylated butadiene-acrylonitrile rubber. Such a structure may affect the morphological and mechanical properties of the resulting nanocomposites. As emphasised by $\mathrm{Wu}$ [45], the interlayer distance in GO sheets is proportional to the degree of oxidation. Generally, the GO sheets with lower $\mathrm{C} / \mathrm{O}$ atomic ratio have higher d-spacing, which can be explained by a higher degree of functionalisation. Consequently, the obtained graphene oxide with carboxylic groups was characterised by a high degree of functionalisation, and so the process of modification of graphene oxide in order to bind carboxylic groups to the particle surface was accomplished successfully.

\section{Examination of nanomaterial structure using FTIR}

The purpose of the research using the Fourier transform infrared spectroscopy (FTIR) method was to confirm the presence of chemical bonds between the filler particles and the polymer matrix of XNBR rubber.

The FTIR spectrum of XNBR rubber, graphene oxide (GO) and bentonite (Bent.) is presented in Fig. 7. Figures 8, 9, 10, and 11 show the FTIR spectra of the XNBR composites without nanofillers and with two types of nanofillers: bentonite, a layered aluminosilicate and graphene oxide.

It should be emphasised that unlike graphene nanoplatelets [46], for graphene oxide noted peaks at $3442,1740 / 1480,1203 \mathrm{~cm}^{-1}$ corresponding to the $-\mathrm{OH}$, $-\mathrm{C}=\mathrm{O} ;-\mathrm{C}=\mathrm{C}-$ and $-\mathrm{C}-\mathrm{O}$ functional groups were noted. The FTIR spectrum of $\mathrm{GO}$ indicated the presence of prominent oxygen containing groups. The broad peak 


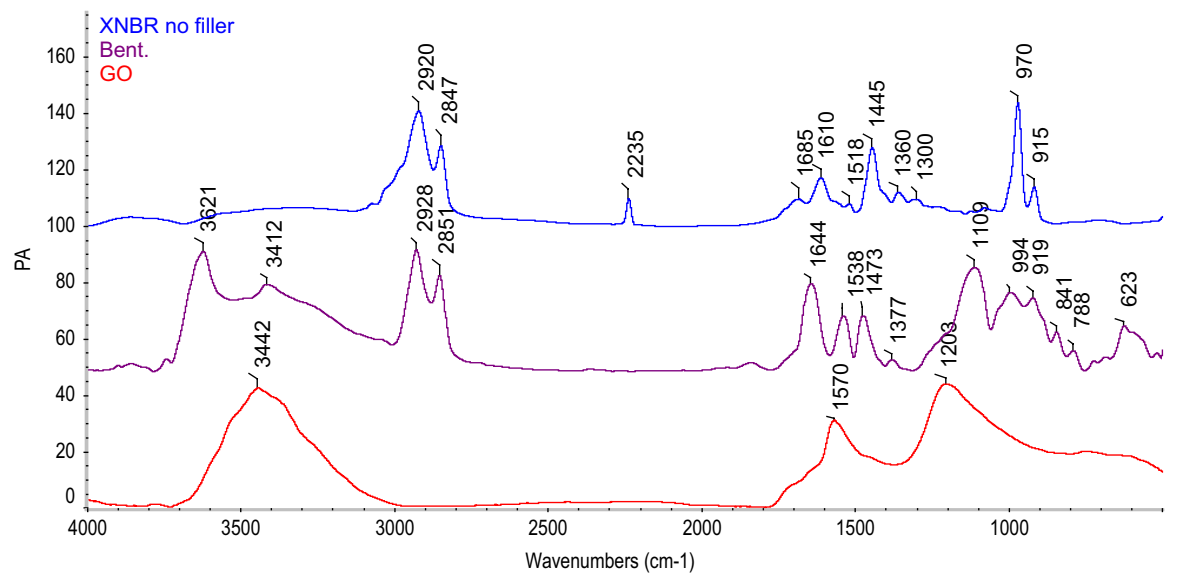

Fig. 7 Summary of photoacoustic spectra of hybrid crosslinked XNBR containing no nanofillers (XNBR no filler) and of nanofillers: graphene oxide with carboxylic groups (GO) and bentonite (Bent)

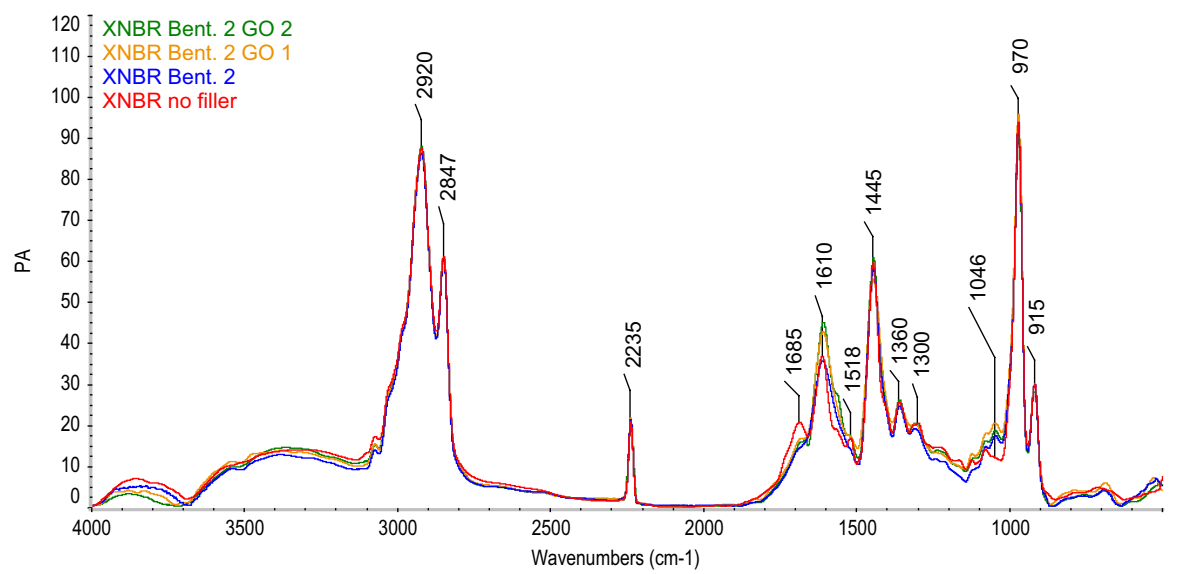

Fig. 8 Summary of photoacoustic spectra of hybrid crosslinked XNBR composites without nanofillers (XNBR) and with the content of nanofillers: graphene oxide with carboxylic groups or bentonite (XNBR Bent. 2; XNBR Bent 2 GO 1; XNBR Bent 2 GO 2) within the 4000-500 $\mathrm{cm}^{-1}$ range

at $3442 \mathrm{~cm}^{-1}$ which could be assigned to the $\mathrm{O}-\mathrm{H}$ stretch from carboxyl groups indicated the existence of adsorbed water molecules and structural $-\mathrm{OH}$ groups of graphite oxide, which was confirmed in the studies conducted by Smaoui [41].

On the basis of the obtained photoacoustic spectra, it was found that the introduction of the fillers: bentonite and GO to XNBR did not affect the symmetric oscillations at $2920 \mathrm{~cm}^{-1}$ and the asymmetric ones at $2847 \mathrm{~cm}^{-1}$ of the $\mathrm{C}-\mathrm{H}$ groups (Figs. 7, 8).

In the photoacoustic spectra of XNBR composites within the range of wave numbers characteristic of oscillations of the $-\mathrm{C} \equiv \mathrm{N}$ group, no significant differences of 


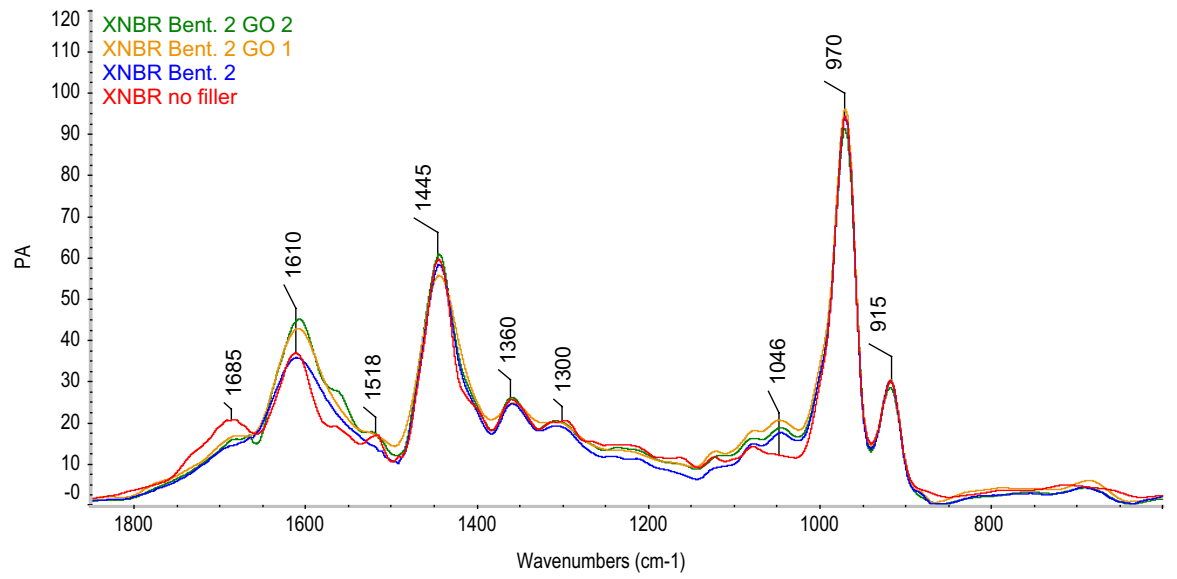

Fig. 9 Summary of photoacoustic spectra of hybrid crosslinked XNBR composites without nanofillers (XNBR) and with the content of nanofillers: graphene oxide with carboxylic groups or bentonite (XNBR Bent. 2; XNBR Bent 2 GO 1; XNBR Bent 2 GO 2) within the $1800-800 \mathrm{~cm}^{-1}$ range

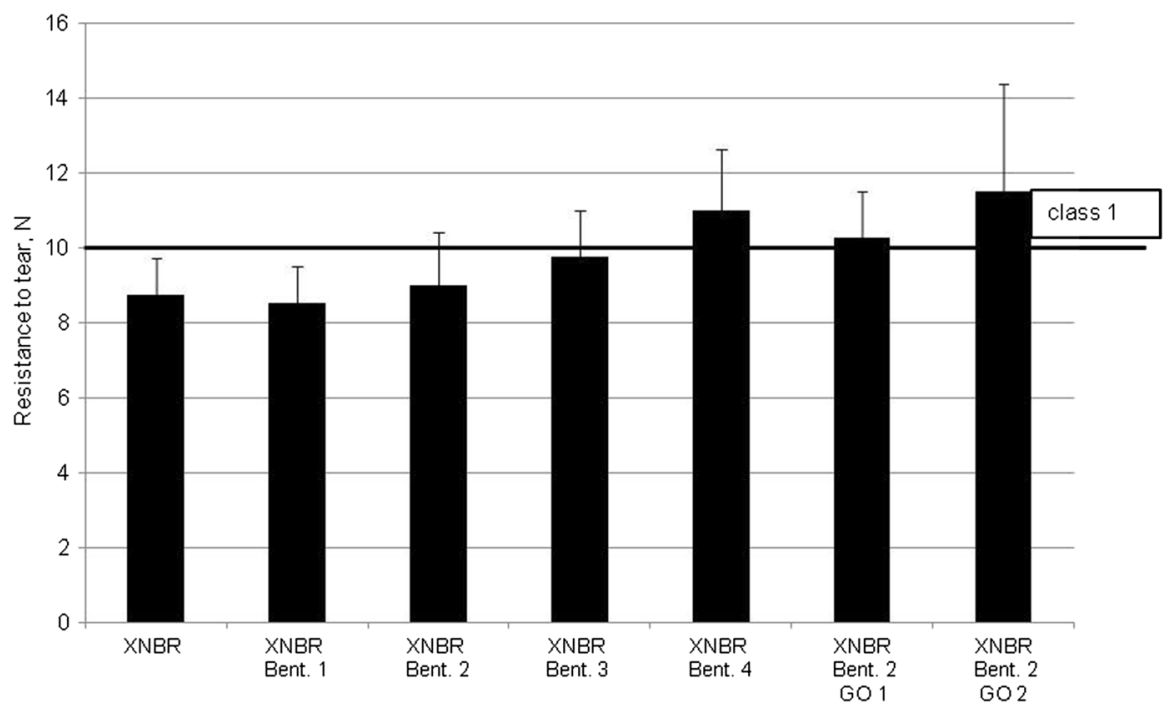

Fig. 10 Effect of the type and amount of the nanofiller introduced to XNBR on tear resistance of the composites

their shape and intensity in relation to the intensity of the $-\mathrm{CH}$ group bands were observed after the introduction of the nanofillers (Fig. 8). A little difference was observed in the case of XNBR Bent 2 GO 2 composite, for which a slight widening of the $-\mathrm{C} \equiv \mathrm{N}$ band is visible. This may be due to structural abnormalities in the XNBR rubber matrix because of different intermolecular interactions caused by the introduction of larger quantities of bentonite and GO. 


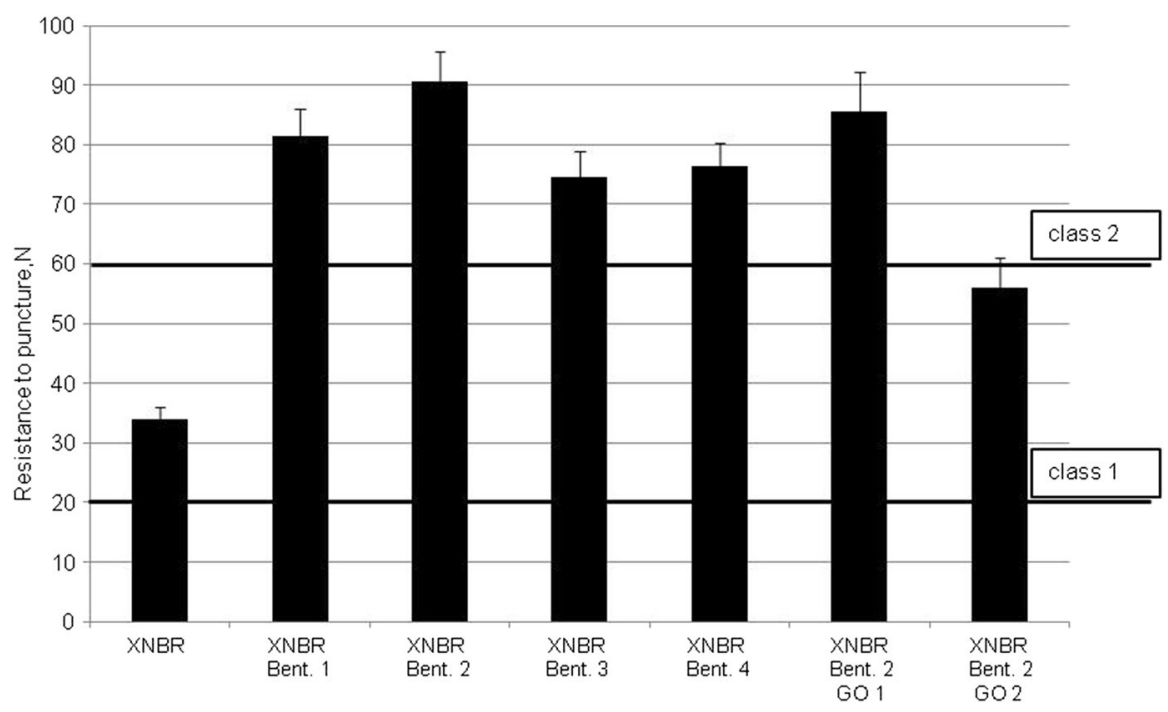

Fig. 11 Effect of the type and amount of the nanofiller introduced to XNBR on puncture resistance of the composites

On the basis of the photoacoustic spectra of XNBR composite containing graphene oxide functionalised with the carboxylic groups, the impact of the nanofiller on the supramolecular structure of the XNBR composite was deduced.

An effect on the oscillator $-\mathrm{C} \equiv \mathrm{N}$ band (approx. $2235 \mathrm{~cm}^{-1}$ ) was observed, indicating that the impact of $-\mathrm{C} \equiv \mathrm{N}$ groups is stronger in comparison with oxygen derivatives of graphene, which in turn could cause a change in the position of the wave numbers on the $-\mathrm{C} \equiv \mathrm{N}$ group spectra in the rubber macromolecules to more exposed on the outside of the agglomerates, which changed the probability of resonance interactions with the measuring beam. The analysis of the photoacoustic spectra of crosslinked XNBR composite indicates a strong impact of nanofiller particles on the $-\mathrm{C}=\mathrm{O}$ oscillator groups (from ca. $1740 \mathrm{~cm}^{-1}$ to ca. $1550 \mathrm{~cm}^{-1}$ ). FTIR studies of SBR (styrene-butadiene rubber) and XNBR/SBR composites containing graphene oxide conducted by Liu, also demonstrated the presence of peaks at 1742 and $1701 \mathrm{~cm}^{-1}$ in the XNBR spectrum corresponding to the stretching vibration of free and hydrogen bonded $-\mathrm{C}=\mathrm{O}$, respectively [47]. The introduction of fillers in the form of $\mathrm{GO}$ and/or bentonite led to a deformation of the rubber chains, which were probably surrounded by nanofiller particles and caused an increase in tensile stress resulting in a shift of $1610 \mathrm{~cm}^{-1}$ resonant frequencies in the composite containing no filler towards the lower wave numbers (Fig. 9) in the composite with such fillers. This may evidence a change in the impact of $-\mathrm{C}=\mathrm{O}$ groups after the introduction mainly of graphene oxide with carboxylic groups to XNBR and indicate a more relaxed structure of the filled composite. Slightly it may result from the incorporation of bentonite. The solidification and supermolecular organisation of polymers depend on many factors. Generally, chains strive to obtain a conformation with the lowest internal energy. The structure is then compact, and the internal stresses 
are low. The introduction of the filler disturbs the supermolecular structure of the polymers causing chain deformations and probable strong interactions between GO molecules and mixture components. This causes intramolecular stresses which were noticed in the spectra in the form of band shifts.

\section{The effect of type and amount of nanofillers on the mechanical properties of XNBR composites}

XNBR composites were tested for resistance to:

- tearing,

- cutting,

- puncture,

- disruption,

- abrasion.

The test results for the investigated mechanical properties of XNBR materials are presented in Figs. 10, 11, 12, and 13.

The results of tests of mechanical parameters have been evaluated in accordance with PN-EN 388:2006 [31], presenting the requirements in the field of mechanical parameters for materials in the form of membranes and all-rubber products (gloves, safety footwear). Such products are required to meet at least one of the mechanical parameters (resistance to abrasion, puncture, tearing, cutting) at the minimum level of protection (class 1). The same parameters, with additionally determined tensile strength, are required for clothing items (protective clothing) manufactured from

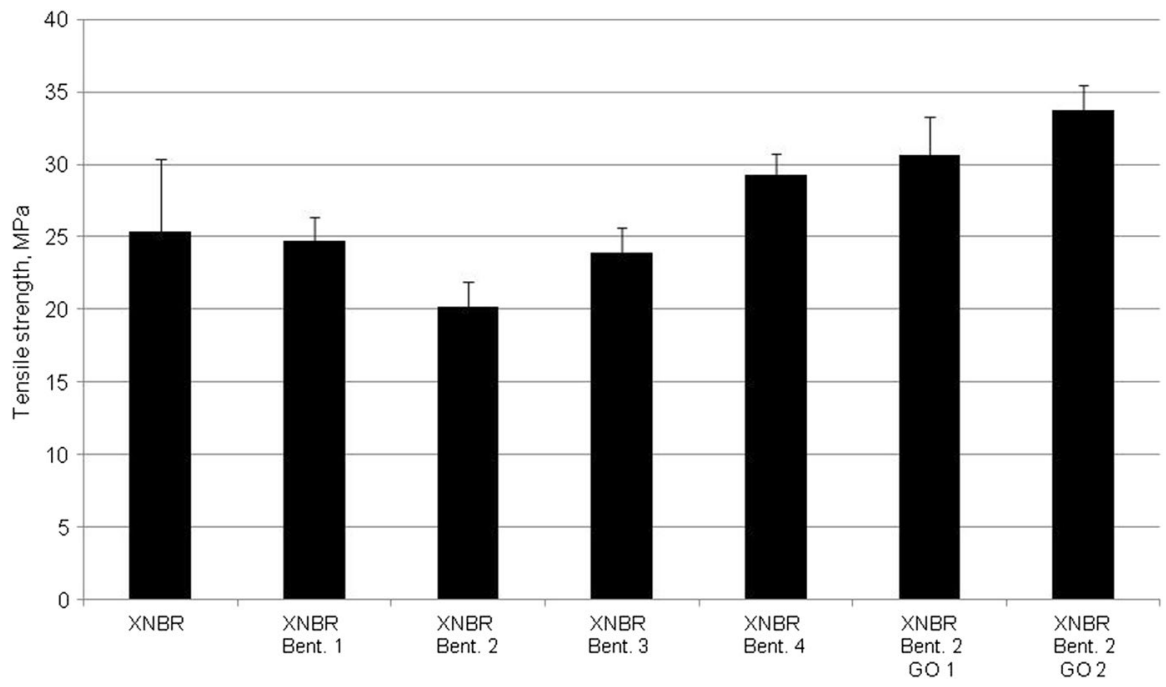

Fig. 12 Effect of the type and amount of the nanofiller introduced to XNBR on tensile strength 


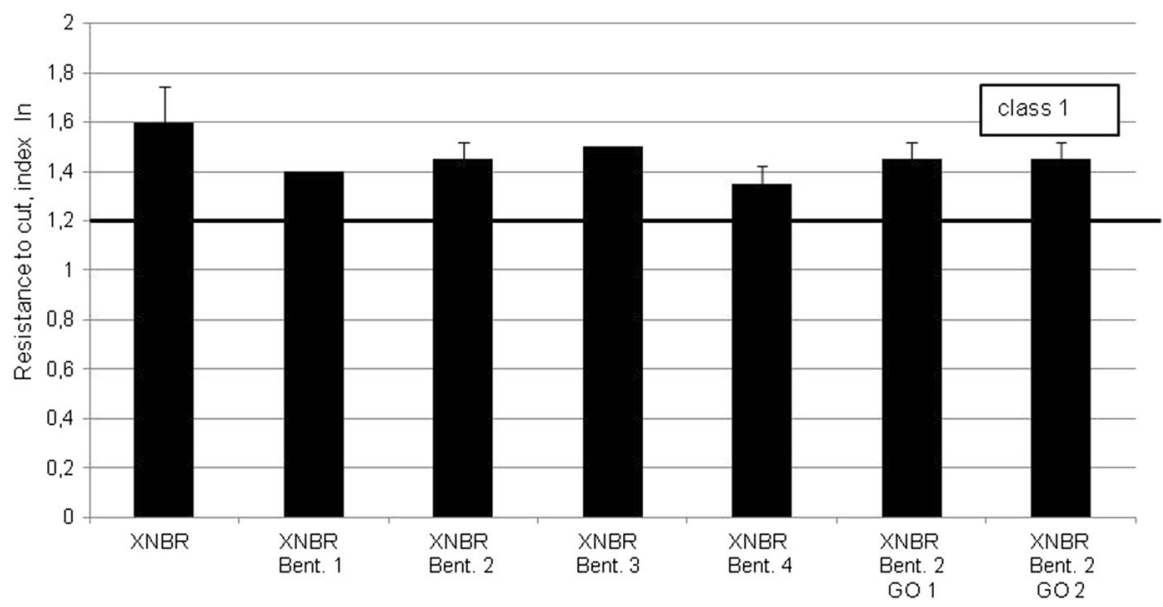

Fig. 13 Effect of the type and amount of the nanofiller introduced to XNBR on cut resistance of the composites

fabrics coated with polymer mixtures. The classification of the parameters is shown in Table 4.

As expected, simultaneous introduction to XNBR of two types of nanofillers, both an aluminosilicate one in the amount of 1.0-4.0 phr and a carbon one in the amount of 1.0-2.0 phr, resulted in beneficial changes in parameters such as resistance to tearing, puncture and tensile strength (Figs. 10, 11, 12).

It was observed that with the increase in bentonite content, the tear resistance increased from $9 \pm 1 \mathrm{~N}$ for the reference composite (XNBR without nanofillers) to $11 \pm 2 \mathrm{~N}$ for the XNBR composite containing the maximum amount of $4 \mathrm{phr}$ (Fig. 10). The introduction of graphene oxide together with bentonite in the same 2 phr quantities of either nanofiller allowed to obtain the tear resistance to tearing of the similar level $-12 \pm 3 \mathrm{~N}$. Statistical analysis demonstrated that the differences are not significant $(p=0.1299)$. The tests indicate that the requirements for protection class 1 in terms of tear resistance are met by XNBR composites containing the total amount of nanofillers of minimum $4 \mathrm{phr}$, regardless of the bentonite and graphene oxide contents. The introduction of smaller amounts of nanofillers to XNBR composite did not improve its resistance to tearing. A different trend was observed in the

Table 4 Classification of mechanical parameters according to PN-EN 388:2006

\begin{tabular}{lllllll}
\hline Parameter & \multicolumn{7}{l}{ Protection class } & & \\
\cline { 2 - 6 } & 1 & 2 & 3 & 4 & 5 & 6 \\
\hline Abrasion resistance, number of cycles & 100 & 500 & 2000 & 8000 & - & - \\
Cutting resistance, index $I_{\mathrm{n}}$ & 1.2 & 2.5 & 5.0 & 10.0 & 20.0 & - \\
Tear resistance, $N$ & 10 & 25 & 50 & 75 & - & - \\
Puncture resistance, $N$ & 20 & 60 & 100 & 150 & - & \\
\hline
\end{tabular}


Table 5 Swelling properties of XNBR materials

\begin{tabular}{|c|c|c|c|c|}
\hline \multirow[t]{2}{*}{ Material } & \multicolumn{2}{|c|}{$\begin{array}{l}\text { Volume swelling } Q_{\mathrm{v}} \text { in toluene }(\mathrm{mL} / \\
\mathrm{mL})\end{array}$} & \multicolumn{2}{|c|}{$\begin{array}{l}\text { Volume swelling } Q_{\mathrm{v}} \text { in 2-butanone } \\
(\mathrm{mL} / \mathrm{mL})\end{array}$} \\
\hline & $\begin{array}{l}\text { Before climatic } \\
\text { ageing }\end{array}$ & $\begin{array}{l}\text { After climatic } \\
\text { ageing }\end{array}$ & $\begin{array}{l}\text { Before climatic } \\
\text { ageing }\end{array}$ & $\begin{array}{l}\text { After exposure } \\
\text { climatic ageing }\end{array}$ \\
\hline XNBR no filler & 2.15 & 1.63 & 3.03 & 2.04 \\
\hline XNBR Bent. 2 & 2.14 & 1.62 & 2.96 & 1.93 \\
\hline XNBR Bent. 2 GO 1 & 1.98 & 1.68 & 2.48 & 2.05 \\
\hline XNBR Bent. 2 GO 2 & 1.89 & 1.74 & 2.46 & 2.07 \\
\hline
\end{tabular}

study by Kuan et al. [46], who after the introduction of graphene nanoplatelets into XNBR rubber composites determined the tearing force. He observed that the tear strength decreased from 1.65 (pure XNBR) to $1.52 \mathrm{MPa}$ (3 phr of graphene added). In contrast to our research, the tear strength of the composites decreased with the increase in graphene content. Kuan associated that with two influences: nonuniform dispersion of the nanofillers in higher loading system and the presence of voids.

The most significant improvement in mechanical strength properties of XNBR composites has been reported for the parameter specifying the puncture resistance. Indeed, the application of any nanofiller caused a significant, almost threefold improvement from $34 \pm 2 \mathrm{~N}$ for unfilled XNBR composite to $91 \pm 5 \mathrm{~N}$ for XNBR composite filled with $2 \mathrm{phr}$ of bentonite (XNBR Bent. 2), or to $86 \pm 7 \mathrm{~N}$ for XNBR composite filled with $2 \mathrm{phr}$ of bentonite and $1 \mathrm{phr}$ of graphene oxide (XNBR Bent 2 GO 1) (Fig. 11). During the statistical analysis, a significant $(p=0.0074)$ difference between the composites was obtained. Materials containing more than 3 phr of fillers were characterised by a smaller, approx. double increase in the resistance to puncture, regardless of whether it was a hybrid composite with two types of nanofillers, or with one type-bentonite. Most of the XNBR composites after the introduction of nanofillers complied with the requirements with respect to resistance to puncture for protection class 2 according to PN-EN 388:2006.

In turn, the XNBR composite containing equal volumes of graphene oxide with carboxylic groups and bentonite -2 phr was characterised by the best resistance to disruption (Fig. 12). Its strength increased by approximately 33\%, from $25.4 \mathrm{MPa}$ to $33.7 \mathrm{MPa}$ (the reference sample, XNBR Bent. 2 GO 2, respectively). Statistical analysis showed a highly significant difference in strength between these composites ( $p=0.0046)$. It has been demonstrated that the use of the same amount ( $2.0 \mathrm{phr})$ of graphene oxide with carboxylic groups and bentonite turned out to be more beneficial than a lower amount of graphene oxide with carboxylic groups (1.0 phr) and the same amount of bentonite (2.0 phr) (Fig. 12). The differences in elongation at break were estimated at approx. 11\%. The introduction of one type of nanofiller-bentonite in 1, 2 or 3 phr quantities, to XNBR composite contributed to an unexpected deterioration of the strength properties. For a composite with the content of bentonite alone in the amount of $2.0 \mathrm{phr}$ (XNBR Bent 2), the determined tensile strength amounted to 20.2 MPa and was approx. $20 \%$ lower in comparison with the reference 
sample. Tensile strength tests by Bharadwaj et al. of styrene-butadiene rubber modified with other type of nanofillers-hectorite indicated similar results.

Similar results were obtained in the study by Das et al. [48], who at the particular level of filling of styrene-butadiene rubber (SBR) mixture with various types of nanoparticles obtained a significant improvement in mechanical properties of the composites. Incorporation of two kinds of nanofillers: carbon nanotubes and expanded graphite, contributed to a rapid growth of the Young modulus and tensile strength. The breaking force increased approx. 4 times, from $2.44 \mathrm{MPa}$ for the samples containing no fillers to $9.66 \mathrm{MPa}$ for the variant with the content of $20 \mathrm{phr}$ expanded graphite and $5 \mathrm{phr}$ carbon nanotubes. A good effect on the mechanical properties was observed when SBR composites were loaded with expanded graphite in the presence of carbon nanotubes. Comparing the values of the breaking force for the composites filled with expanded graphite in the same 20 phr quantity and carbon nanotubes in quantities ranging from 0.5 to $5 \mathrm{phr}$ demonstrated clearly that with the increased content of carbon nanotubes the breaking force increased. Compounds loaded with $20 \mathrm{phr}$ of expanded graphite or carbon nanotubes showed a moderate value of tensile strength which was achieved only by incorporation of high amount of traditional silica. In another study, Zhang observed that mechanical properties of XNBR/SBR blends with different contents of graphene oxide (GO) were remarkably improved with the increase in GO loading, similar to our tests. The tensile strength and tear strength for $\mathrm{XNBR} / \mathrm{SBR} / \mathrm{GO}$ blend with $0.3 \mathrm{phr}$ GO were significantly enhanced by $71 \%$ and $94 \%$, respectively, compared with those of neat XNBR/SBR blend. The authors observed the improved compatibility between XNBR and SBR induced by GO [49].

According to Ponnamma [50], mechanical performance of elastomer nanocomposites depends on several factors such as the filler dispersion, the degree of interfacial adhesion between the elastomers and the filler, as well as the crosslink density of the composite. For the analysis of mechanical strength properties (tear resistance, cutting resistance and tensile strength) of XNBR composites with the content of both types of nanofillers, structural studies can be helpful. The WAXS results showed that in the case of the introduction of graphene oxide with carboxylic groups to XNBR as one of the two fillers used, in view of the absence of the characteristic peak on the WAXS curve, exfoliation between the graphene layers had occurred. It was therefore concluded that the structure had not been destroyed in the process of GO Introduction to the XNBR mix, which is a very positive effect and might have improved the mechanical properties. It is noteworthy that this is a good result, because the earlier studies failed to obtain a significant improvement in mechanical properties [51].

The authors believe that a factor that contributed to this was also the change of XNBR crosslinking method from using sulphur alone to using a hybrid set: sulphur + magnesium oxide.

Sadasivuni et al. [52], investigating X-ray diffraction of butyl rubber (IIR) composites, in which they introduced separately $5 \mathrm{phr}$ of aluminosilicate (Closite 10) or graphene (thermally reduced graphene-TRG), observed that the diffraction attributed to natural graphite $\left(2 \theta=26.5^{\circ}\right)$ had not occurred in the XRD spectrum for butyl rubber composite with graphene content, which indicated in his opinion 
an exfoliation of graphene within the IIR matrix of. Sadasivuni, like the authors, reported a significant increase in mechanical properties, with the tensile strength at break reinforced most significantly. He observed an increase in tensile strength from 2 to more than 4 times compared to unfilled IIR (unfilled IIR 0.8 MPa, IRR/ Closite max 3.5 MPa, IRR/graphene 2.7 MPa). It was determined that greater tensile strength was accompanied by greater Young's modulus of IIR/graphene (approx. 2.4 times higher than that of the unfilled matrix). In rubber, there were the strong interactions between the rubber and the filler. The interactions were stronger between IIR and graphene than between IIR and clay. The high specific surface area and the two-dimensional geometry of graphene resulted in improved mechanical interlocking and adhesion with polymeric chains complex [52]. According to Sadasivuni, due to the high aspect ratio and good filler-polymer interactions, the graphene nanocomposites exhibit a good enhancement in Young's, storage modulus and a decrease in oxygen permeability.

However, not all the parameters characterising the mechanical properties were improved. In the case of testing the resistance to cutting, the test results, regardless of the type and amount of nanofillers introduced to XNBR blend, showed a slight (approx. 6\%) deterioration of resistance of the composites compared to the reference samples with no fillers. For all variants, the obtained values were at a similar level, located within the cutting index $\mathrm{I}_{\mathrm{n}}$ range from $1.4 \pm 0$ to $1.5 \pm 0.1$, compared to the reference sample, for which the resistance to cutting was $I_{\mathrm{n}}=1.6 \pm 0.1$. Statistical analysis demonstrated that the differences were not significant $(p=0.2020)$. All the variants of composite materials met the requirements of class 1 according to PN-EN 388:2006 (Fig. 13).

The abrasion resistance both for the reference sample without the nanofiller content (XNBR), and for the composites containing nanofillers remained at the same, unchanged level of 8000 cycles, corresponding to the highest protection class 4 according to PN-EN 388:2006. Statistical analysis showed no variability.

\section{The effect of type and amount of nanofillers on the barrier properties of XNBR composites}

Acrylonitrile-butadiene rubber composites crosslinked with magnesium oxide and sulphur, containing two types of nanofillers: a carbon one (graphene oxide with carboxylic groups i) in the amount of 1 or $2 \mathrm{phr}$ and/or an aluminosilicate one (bentonite) in 1, 2, 3, or 4 phr quantity, revealed equally high resistance to penetration by oil-more than $480 \mathrm{~min}$. (The test was conducted for up to $480 \mathrm{~min}$.) This result corresponds to the highest protection class 6 according to PN-EN 14605:2008 [34] and PN-EN 374-1:2005 [35] containing the requirements for materials designed to protect against chemicals.

The addition of carbon nanofillers (graphene oxide with $\mathrm{COOH}$ groups) or an aluminosilicate nanofiller (modified bentonite) to the XNBR did not affect the barrier properties of the cured compounds. The breakthrough time for XNBR composites without the nanofiller and containing differential amounts of the nanofiller was 
very long and similar to the reference sample (480 $\mathrm{min})$. This indicated very good barrier properties of XNBR composites against mineral oil.

The barrier properties of XNBR composites were also characterised by resistance to swelling in two solvents: toluene and 2-butanone. Swelling is considered to be one of the key parameters that define the resistance of polymer composites to chemicals. The fact that with a decrease in swelling, the crosslinking density increases and then the mechanical properties of composites are improved is noteworthy. This trend is in harmony with the tensile strength and the increment in torque, which provides further confirmation that the used nanofillers may play a role not only as a reinforcing filler but also as a curative agent for functionalised elastomers such as XNBR [41].

Volume swelling was determined for new composite samples and after climatic ageing. It involved exposure to a xenon lamp $(\lambda=300-400 \mathrm{~nm})$ for a period of $400 \mathrm{~h}$ at radiation intensity of $50 \mathrm{~W} / \mathrm{m}^{2}$ and $90 \%$ relative humidity, at $20{ }^{\circ} \mathrm{C}$ temperature during the day and with the xenon lamp turned off at night. Generally, the XNBR composite without a filler (XNBR No filler) is characterised by minimally higher swelling than XNBR composites with nanofillers. This applied to the tests with both solvents. It was observed that with an increase in the filler content, the equilibrium swelling of the composites was subject to reduction: from $2.15 \mathrm{~mL} / \mathrm{mL}$ for the reference sample without fillers to $1.89 \mathrm{~mL} / \mathrm{mL}$ for the composite containing two types of fillers in equal quantities of $2 \mathrm{phr}$ in the case of toluene tests, and $3.03 \mathrm{~mL} / \mathrm{mL}$ for the reference sample without fillers to $2.46 \mathrm{~mL} / \mathrm{mL}$ for the composite containing two types of fillers in equal quantities of $2 \mathrm{phr}$ in the case of tests with 2-butanone (Table 5).

In the case of swelling in toluene, the maximum difference is $0.26 \mathrm{~mL} / \mathrm{mL}$ composite with the content of two types of fillers in equal quantities of 2 phr. For the same, twice higher swelling- $0.67 \mathrm{~mL} / \mathrm{mL}$ was determined when 2-butanone was used. It indicates that the reference sample is slightly less densely crosslinked than the composites with nanofillers. This may suggest that the presence of bentonite and graphene oxide makes the formation of networks in the rubber matrix more difficult. Even a slight reduction in swelling, resulting in an increase in the crosslinking density, influenced the improvement of mechanical properties of the resistance to tear and puncture (Figs. 10, 11).

Climatic ageing contributed to a reduction of the equilibrium volume swelling ratio. Swelling in toluene was reduced from 8 to $25 \%$, and in 2-butanone from 20 to $30 \%$. Simulated ageing of the composite was observed to influence its properties positively.

Likewise, the mole per cent uptake was adopted by Liu for determination of the solvent resistance of rubber nanocomposites [47]. For tests Liu used toluene as the solvent for the tests.

It can be seen that mole per cent uptake of SBR and XNBR/SBR composites with graphene oxide decreases significantly with the addition of the filler, from 4.25 for composite with no filler to $3.25 \mathrm{~mol} / 100 \mathrm{~g}$ for both types of composites with $4 \mathrm{phr}$ of GO. Liu came to similar conclusions that graphene oxide (GO), a filler with a high aspect ratio, acts as an impenetrable barrier in the matrix, leading to the difficulty of 
Table 6 Results of puncture resistance tests of XNBR composites before and after exposure to seawater substitute

\begin{tabular}{|c|c|c|}
\hline \multirow[t]{2}{*}{ Composite } & \multicolumn{2}{|c|}{ Puncture resistance, $N$} \\
\hline & $\begin{array}{l}\text { Before exposure to } \\
\text { seawater }\end{array}$ & $\begin{array}{l}\text { After } \\
\text { exposure to } \\
\text { seawater }\end{array}$ \\
\hline XNBR Bent. 2 & 37.0 & 57.5 \\
\hline XNBR Bent. 2 GO 1 & 45.0 & 49.3 \\
\hline XNBR Bent. 2 GO 2 & 41.0 & 83.9 \\
\hline
\end{tabular}

solvent diffusion and low mole per cent uptake value. So it is a beneficial phenomenon, resulting in improved resistance to chemicals.

For testing resistance to seawater, hybrid XNBR composites containing both types of nanofillers, or bentonite only, i.e. marked with symbols XNBR Bent. 2 GO 1, XNBR Bent. 2 GO 2 and XNBR Bent. 2, were selected. The composites were observed to change their colouring. The composite with bentonite content changed its colour from dark beige to a much lighter shade of beige with slightly orangish hue after 12 weeks of exposure to seawater substitute solution. The composite containing carboxylated graphene oxide and bentonite exposed to seawater substitute solution changed its colour from dark grey (almost black) to a much lighter shade of grey. Numerous discolourations in the form of irregular streaks and scratches were observed (Fig. 3 in Supporting Information). It means that the tested materials underwent discolouration in the seawater substitute medium, which contains various salts, mainly sodium chloride and magnesium chloride, sodium sulphate, calcium and potassium chlorides. The duration of the materials contact with the solution was important. The longer it was, the more significant changes occurred on the surface of the composites. More and more discolourations were observed in each consecutive week. The biggest differences can be observed in the surface and colour if the tested materials were observed after 12 weeks (maximum time) of exposure to seawater medium. No clear stiffening of the composites can be observed. Tests of a selected mechanical parameter demonstrated with high probability that as a result of leaching of the components the structure became more rigid, resulting in increased resistance to puncture (Table 6).

\section{Conclusions}

Simultaneous introduction to XNBR of two types of nanofillers, modified bentonite as an aluminosilicate nanofiller in the amount of 1.0-4.0 phr and graphene oxide with carboxylic groups as a carbon nanofiller in the amount of 1.0-2.0 phr, affected positively the mechanical parameters: resistance to tearing, puncture and tensile strength.

The most significant improvement has been noted for the parameter specifying the puncture resistance. Indeed, the application of any nanofiller caused a significant, almost threefold improvement from $34 \pm 2 \mathrm{~N}$ for unfilled XNBR composite to 
$86 \pm 7 \mathrm{~N}$ for XNBR composite filled at the same time with $2 \mathrm{phr}$ of bentonite and 1 phr of graphene oxide, modified towards the introduction of carboxylic groups. The tensile strength of XNBR composites containing equal volumes of graphene oxide and bentonite ( $2 \mathrm{phr}$ ) increased significantly, by approx. 33\%, from 25.4 to $33.7 \mathrm{MPa}$ (the reference sample, XNBR Bent. 2 GO 2, respectively). The application of equal amounts ( 2 phr) of either nanofiller allowed also to increase the resistance to tearing from $9 \pm 1$ to $12 \pm 3 \mathrm{~N}$. Introduction of smaller amounts of nanofillers to XNBR composite did not improve its tear resistance.

The manufactured composites containing at the same time two types of nanofillers have revealed equally high resistance to penetration by the selected chemical-mineral oil. The breakthrough time for XNBR composites without a nanofiller and containing differential amounts of nanofillers was very long and similar to the reference sample (480 min). This indicated very good barrier properties of XNBR composites against mineral oil. The barrier properties of XNBR composites were characterised also by determination of their resistance to swelling in two solvents: toluene, and 2-butanone. A slight reduction in swelling, resulting in the improvement of the mechanical properties, has been observed.

Wide-angle X-ray scattering (WAXS) examination of the XNBR composites with both nanofillers showed that the lack of the characteristic graphene oxide peak $\left(2 \Theta \approx 10.6^{\circ}\right)$ on the curve and therefore indicated exfoliation between the graphene layers. In the case of the other nanofiller, bentonite, a reduction of the distance between the layers in the form of powder and the produced composites (from 1.80 to $1.37 \mathrm{~nm}$ ) has been observed, regardless of the degree of filling of the composites that may promote the formation of agglomerates.

Acknowledgements The present publication is based on the results of Phase III of the National Programme "Safety and working conditions improvement" funded in the years 2014-2016 in the area of research and development work by the Ministry of Science and Higher Education/The National Centre for Research and Development. The programme's coordinator is the Central Institute for Labour Protection-National Research Institute.

Open Access This article is distributed under the terms of the Creative Commons Attribution 4.0 International License (http://creativecommons.org/licenses/by/4.0/), which permits unrestricted use, distribution, and reproduction in any medium, provided you give appropriate credit to the original author(s) and the source, provide a link to the Creative Commons license, and indicate if changes were made.

Open Access This article is distributed under the terms of the Creative Commons Attribution 4.0 International License (http://creativecommons.org/licenses/by/4.0/), which permits unrestricted use, distribution, and reproduction in any medium, provided you give appropriate credit to the original author(s) and the source, provide a link to the Creative Commons license, and indicate if changes were made.

\section{References}

1. Kang H, Zuo K, Wanga Z, Zhang L, Liu L, Guo B (2014) Using a green method to develop graphene oxide/elastomers nanocomposites with combination of high barrier and mechanical performance. Compos Sci Technol 92:1-8. https://doi.org/10.1016/j.compscitech.2013.12.004 
2. Potts JR, Shankar O, Du L, Ruoff RS (2012) Processing-morphology-property relationships and composite theory analysis of reduced graphene oxide/natural rubber nanocomposites. Macromolecules 45:6045-6055. https://doi.org/10.1021/ma300706k.pubs.acs.org/Macromolecules

3. Okamoto M (2003) Polymer/layed silicate nanocomposites. Rapra Rev Rep 14:1-50

4. Olejnik M (2008) Polymeric nanocomposites with montmorillonite content-methods of obtaining, assessment, properties and application. Tech Text Prod 16:67-74

5. Kurzydłowski K, Lewandowska M (2011) Engineering nanomaterials. Structural and functional. Scientific Publisher (Wydawnictwo Naukowe) PWN, Warsaw

6. Gołębiewski J, Różański A, Gałęski A (2006) Study on the process of preparation of polypropylene nanocomposite with montmorillonite. Polimery 51:376-381

7. Leite IF, Soares APS, Carvalho LH, Raposo CMO, Malta OML, Silva SML (2010) Characterization of pristine and purified organobentonites. J Therm Anal Calorim 100:563-569. https://doi. org/10.1007/s10973-009-0265-3

8. Królikowski W, Rosłaniec Z (2004) Polymeric nano-composites. Composites 9:3-15

9. Ma J, Qi J, Yao Ch, Cui B, Zhang T, Li D (2012) A novel bentonite-based adsorbent for anionic pollutant removal from water. Chem Eng J 200-202:97-103. https://doi.org/10.1016/j.cej.2012.06.014

10. Hedley CB, Yuan G, Theng BKG (2006) Thermal analysis of montmorillonites modified with quaternary phosphonium and ammonium surfactants. Appl Clay Sci 35(3):180-188. https://doi. org/10.1016/j.clay.2006.09.005

11. Gołębiewski J (2004) Polymeric nanocomposites. Structure, production methods and properties. Przem Chem 83:15-20

12. Choubak S, Levesque PL, Gaufres E, Biron M, Desjardins P, Martel R (2014) Graphene CVD: interplay between growth and etching on morphology and stacking by hydrogen and oxidizing impurities. J Phys Chem C 118(37):21532-21540. https://doi.org/10.1021/jp5070215

13. Xu X, Zhang Z, Dong J, Yi D, Niu J, Wu M et al (2017) Ultrafast epitaxial growth of metre-sized single-crystal graphene on industrial Cu foil. Sci Bull 62(15):1074-1080. https://doi.org/10.1016/j. scib.2017.07.005

14. ISO/TS 80004-13:2017 Nanotechnologies. Vocabulary. Part 13: graphene and related two-dimensional (2D) materials

15. Gao W (2015) The chemistry of graphene oxide. In: Gao W (ed) Graphene oxide. Springer, Cham, pp 61-97. https://doi.org/10.1007/978-3-319-15500-5_3

16. Heneczkowski M, Szczepanowska M, Galina H, Groszek G, Mental Z, Oleksy M, Wojcik Z, Krawczyk B (2000) Thixotropic unsaturated polyester resin composition of improved stability and method of obtaining same. Patent B PL178900B. Patent Office of the Republic of Poland, Warsaw

17. Heneczkowski M, Szczepanowska M, Galina H, Groszek G, Mental Z, Oleksy M, Wojcik Z, Krawczyk B (2000) Unsaturated polyester resin composition of improved stability and method of obtaining same. Patent B. PL178866B. Patent Office of the Republic of Poland, Warsaw

18. Žunić M, Milutinović-Nikolić A, Nastasović A, Vuković Z, Lončarević D, Vuković I, Loos K, ten Brinke G, Jovanovi D (2013) Textural properties of poly(glycidyl methacrylate): acid-modified bentonite nanocomposites. Polym Bull 70:1805-1818. https://doi.org/10.1007/s00289-013-0924-1

19. Ghorbanpour M (2018) Soybean oil bleaching by adsorption onto bentonite/iron oxide nanocomposites. J Phys Sci 29(2):113-119. https://doi.org/10.21315/jps2018.29.2.7

20. Occelli ML, Tindawa RM (1983) Physicochemical properties of montmorillonite interlayered with cationic oxyaluminum pillars. Clays Clay Miner 31(1):22-28

21. Patterson AL (1939) The Scherrer formula for X-ray particle size determination. Phys Rev 56:978-982

22. Oh YJ, Yoo JJ, Kim YI, Yoon JK, Yoon HN, Kim JH, Park SB (2014) Oxygen functional groups and electrochemical capacitive behavior of incompletely reduced graphene oxides as a thinfilm electrode of Supercapacitor. Electrochim Acta 116:118-128. https://doi.org/10.1016/j.elect acta.2013.11.040

23. Perumbilavil S, Pranitha Sankar P, Rose TP, Philip R (2015) White light Z-scan measurements of ultrafast optical nonlinearity in reduced graphene oxide nanosheets in the 400-700 nm region. Appl Phys Lett 107:051104. https://doi.org/10.1063/1.4928124

24. Kaniyoor A, Ramaprabhu S (2012) A Raman spectroscopic investigation of graphite oxide derived graphene. AIP Adv 2(032183):1-13. https://doi.org/10.1063/1.4756995

25. Ferrari AC, Meyer JC, Scardaci V, Casiraghi C, Lazzeri M, Mauri F, Piscanec S, Jiang D, Novoselov KS, Roth S, Geim AK (2006) Raman spectrum of graphene and graphene layers. Phys Rev Lett 97(18):187401. https://doi.org/10.1103/PhysRevLett.97.187401 
26. Sing K (2001) The use of nitrogen adsorption for the characterisation of porous materials. Colloids Surf A 187-188:3-9. https://doi.org/10.1016/s0927-7757(01)00612-4

27. Dai JF, Wang GJ, Ma L, Wu ChK (2015) Surface properties of graphene: relationship to graphenepolymer composites. Rev Adv Mater Sci 40(1):60-71

28. Krzemińska S, Rzymski W, Smejda-Krzewicka A, Lipińska L, Woluntarski M, Oleksy M (2016) Elastomer composition of carboxylated butadiene acrylonitrile rubber. Patent Application No. P.419470. Patent Office of the Republic of Poland, Warsaw

29. PN-ISO 3417:1994 Rubber compound. Determination of the course of vulcanisation by using a vulcametre with an oscillating rotor

30. PN ISO 37:1998 Rubber and thermoplastic rubber. Determination of tensile stress-strain properties

31. PN-EN 388:2006 Protective gloves against mechanical hazards

32. PN-EN 374-3:2005 Protective gloves against chemicals and micro-organisms. Part 3: determination of resistance to permeation by chemicals

33. PN-EN 6529:2005/AC: 2006 Protective clothing. Protection against chemicals. Determination of resistance of protective clothing materials to permeation by liquids and gases

34. PN-EN 14605:2008 Protective clothing against liquid chemicals. Requirements for clothing providing full body protection, with connections impermeable for liquids in liquid form (type 3) or spray (type 4), including products providing only partial protection of the body (types PB [3] and PB [4])

35. PN-EN 374-1:2005 Protective gloves against chemicals and micro-organisms. Part 1: Terminology and performance requirements for chemical risks

36. PN-EN ISO 9377-2:2003 Quality of water Determination of the mineral oil index. Part 2: Method using solvent extraction and gas chromatography

37. Krzemińska S, Rzymski WM, Malesa M, Borkowska U, Oleksy M (2016) Gloves against mineral oils and mechanical hazards. Int J Occup Saf Ergon 22(3):350-359. https://doi.org/10.1080/10803 548.2015.1136111

38. PN-ISO 1817:2001 Rubber. Determination of resistance to liquids

39. Krzemińska S, Rzymski WM (2011) Barrier properties of hydrogenated acrylonitrile-butadiene rubber composites containing modified layered aluminosilicates. Mater Sci Pol 29(4):285-291. https:// doi.org/10.2478/s13536-011-0046-0

40. PN-C-06502:1966 Sea water substitute

41. Laskowska A, Zaborski M, Boiteux G, Gain O, Marzec A, Maniukiewicz W (2014) Ionic elastomers based on carboxylated nitrile rubber (XNBR) and magnesium aluminum layered double hydroxide (hydrotalcite). eXPRESS Polym Lett 8(6):374-386. https://doi.org/10.3144/expresspol ymlett.2014.42

42. Smaoui I, Domatti A, Kharrat M, Dammak M, Monteil G (2016) Eco-friendly nanocomposites between carboxylated acrylonitrile-butadiene rubber (XNBR) and graphene oxide or graphene at low content with enhanced mechanical properties. Fuller Nanotubes Carbon Nanostruct 24(12):769778. https://doi.org/10.1080/1536383X.2016.1170011

43. Ju HM, Huh SH, Choi SH, Lee HL (2014) Structures of thermally and chemically reduced graphene. Mater Lett 64(3):357-360. https://doi.org/10.1016/j.matlet.2009.11.016

44. Alanyalioğlu M, Segura JJ, Oró-solè J, Casañ-Pastor N (2012) The synthesis of graphene sheets with controlled thickness and order using surfactant-assisted electrochemical processes. Carbon 50(1):142-152. https://doi.org/10.1016/j.carbon.2011.07.064

45. Wu X, Lin TF, Tang ZH, Guo BC, Hua GS (2015) Natural rubber/graphene oxide composites: effect of sheet size on mechanical properties and strain-induced crystallization behavior. eXPRESS Polym Lett 9(8):672-685. https://doi.org/10.3144/expresspolymlett.2015.63

46. Kuan C-F, Chiang C-L, Lin S-H, Huang W-G, Hsieh W-Y, Shen M-Y (2018) Characterization and properties of graphene nanoplatelets/XNBR nanocomposites. Polym Polym Compos 26(1):59-67

47. Liu P, Zhang X, Jia H, Yin Q, Wang J, Yin B, Xu Z (2017) High mechanical properties, thermal conductivity and solvent resistance in graphene oxide/styrene-butadiene rubber nanocomposites by engineering carboxylated acrylonitrile-butadiene rubber. Compos B 130:257-266. https://doi. org/10.1016/j.compositesb.2017.07.048

48. Das A, Kasaliwal GR, Jurk R, Boldt R, Fischer D, Stöckelhuber KW, Heinrich G (2012) Rubber composites based on graphene nanoplatelets, expanded graphite, carbon nanotubes and their combination: a comparative study. Compos Sci Technol 72:1961-1967. https://doi.org/10.1016/j.comps citech.2012.09.005

49. Zhang X, Xue X, Yin Q, Jia H, Wang J, Ji Q, Xu Z (2017) Enhanced compatibility and mechanical properties of carboxylated acrylonitrile butadiene rubber/styrene butadiene rubber by using 
graphene oxide as reinforcing filler. Compos B 111:243-250. https://doi.org/10.1016/j.composites b.2016.12.003

50. Ponnamma D, Maria HJ, Chandra AK, Thomas S (2013) Rubber nanocomposites: latest trends and concepts. In: Visakh PM, Thomas S, Chandra AK, Mathew AP (eds) Advances in elastomers II composites and nanocomposites. Springer, Berlin, pp 9-107. https://doi.org/10.1007/978-3-64220928-4_3

51. Krzemińska S, Smejda-Krzewicka A, Leniart A (2018) Use of carbon and aluminosilicate nanofillers in XNBR composites designed for protective materials against oils. Pol J Chem Technol 20(2):15-23. https://doi.org/10.2478/pjct-2018-0018

52. Sadasivuni KK, Ponnamma D, Thomas S, Grohens Y (2014) Evolution from graphite to graphene elastomer composites. Prog Polym Sci 39(4):749-780. https://doi.org/10.1016/j.progpolyms ci.2013.08.003

Publisher's Note Springer Nature remains neutral with regard to jurisdictional claims in published maps and institutional affiliations.

\section{Affiliations}

\section{Sylwia Krzemińska ${ }^{1}$ (D) Ludwika Lipińska² $\cdot$ Michał Woluntarski ${ }^{2}$ Mariusz Oleksy ${ }^{3} \cdot$ Czesław Ślusarczyk $^{4} \cdot$ Włodzimierz Biniaś $^{4}$. Aleksandra Smejda-Krzewicka ${ }^{5}$}

Sylwia Krzemińska

sykrz@ ciop.lodz.pl

1 Central Institute for Labour Protection-National Research Institute (CIOP-PIB), Czerniakowska 16, 00-701 Warsaw, Poland

2 Institute of Electronic Materials Technology (ITME), Wólczyńska 133, 01-919 Warsaw, Poland

3 Faculty of Chemistry, Rzeszow University of Technology, Al. Powstańców Warszawy 6, 35-959 Rzeszow, Poland

4 University of Bielsko-Biala, Willowa 2, 43-309 Bielsko-Biała, Poland

5 Institute of Polymer and Dye Technology, Lodz University of Technology, Stefanowskiego 12/16, 90-924 Lodz, Poland 